Review Article

\title{
Melatoninergic System in Parkinson's Disease: From Neuroprotection to the Management of Motor and Nonmotor Symptoms
}

\author{
Josiel Mileno Mack, ${ }^{1}$ Marissa Giovanna Schamne, ${ }^{1}$ Tuane Bazanella Sampaio, ${ }^{1}$ \\ Renata Aparecida Nedel Pértile, ${ }^{2}$ Pedro Augusto Carlos Magno Fernandes, ${ }^{3}$ \\ Regina P. Markus, ${ }^{3}$ and Rui Daniel Prediger ${ }^{1}$ \\ ${ }^{1}$ Department of Pharmacology, Centre of Biological Sciences, Universidade Federal de Santa Catarina (UFSC), \\ Campus Universitário, Florianópolis, SC, Brazil \\ ${ }^{2}$ Queensland Brain Institute, University of Queensland (UQ), Brisbane, QLD, Australia \\ ${ }^{3}$ Department of Physiology, Institute of Bioscience, University of São Paulo (USP), São Paulo, SP, Brazil \\ Correspondence should be addressed to Rui Daniel Prediger; rui.prediger@ufsc.br
}

Received 13 July 2016; Accepted 25 September 2016

Academic Editor: Serafina Perrone

Copyright (C) 2016 Josiel Mileno Mack et al. This is an open access article distributed under the Creative Commons Attribution License, which permits unrestricted use, distribution, and reproduction in any medium, provided the original work is properly cited.

\begin{abstract}
Melatonin is synthesized by several tissues besides the pineal gland, and beyond its regulatory effects in light-dark cycle, melatonin is a hormone with neuroprotective, anti-inflammatory, and antioxidant properties. Melatonin acts as a free-radical scavenger, reducing reactive species and improving mitochondrial homeostasis. Melatonin also regulates the expression of neurotrophins that are involved in the survival of dopaminergic neurons and reduces $\alpha$-synuclein aggregation, thus protecting the dopaminergic system against damage. The unbalance of pineal melatonin synthesis can predispose the organism to inflammatory and neurodegenerative diseases such as Parkinson's disease (PD). The aim of this review is to summarize the knowledge about the potential role of the melatoninergic system in the pathogenesis and treatment of PD. The literature reviewed here indicates that PD is associated with impaired brain expression of melatonin and its receptors $\mathrm{MT}_{1}$ and $\mathrm{MT}_{2}$. Exogenous melatonin treatment presented an outstanding neuroprotective effect in animal models of PD induced by different toxins, such as 6-hydroxydopamine (6-OHDA), 1-methyl-4-phenyl-1,2,3,6-tetrahydropyridine (MPTP), rotenone, paraquat, and maneb. Despite the neuroprotective effects and the improvement of motor impairments, melatonin also presents the potential to improve nonmotor symptoms commonly experienced by PD patients such as sleep and anxiety disorders, depression, and memory dysfunction.
\end{abstract}

\section{Introduction}

Parkinson's disease (PD) is a chronic and progressive neurodegenerative disease, characterized by the degeneration of dopaminergic (DAergic) neurons in the substantia nigra pars compacta $(\mathrm{SNc})$ and the subsequent decrease of dopamine (DA) levels in the striatum. PD is classically considered a complex motor disorder, related to the pronounced degeneration of the DAergic system, which manifests in bradykinesia, tremor, rigidity, and postural instability. Nowadays, PD is considered a progressive multisystem disease that affects a variety of neurotransmitters, being linked with nonmotor symptoms, such as impaired olfaction and gastrointestinal, genitourinary, cardiovascular, and respiratory dysfunctions, as well as visual, neuropsychiatric, and sleep-related disorder. Contrary to the well-defined motor symptoms, PD nonmotor signals and symptoms are still poorly understood and almost not considered in diagnostic and therapeutic protocols. Recent studies suggest that the nonmotor preclinical phase can span for more than 20 years.

New pharmacological tools for treating PD focus on the relief of symptoms that are observed when the disease is clinically developed. The development of neuroprotective drugs and therapies for impairing the progression or even 
reducing the extension of the disease needs to rely on the understanding of neuroprotection. Neuroprotection definition is complex and involves the potential for preventing cell death, restoring function of damaged neurons, and increasing neuronal number. The development of drugs to slow or prevent the progression of PD might logically evolve from an improved understanding of the pathogenesis of such disease. In the past few years, certainly there were major advances in this area, improving the prospect for the introduction of neuroprotective therapies. However, despite extensive efforts and research, to date, there is no proven therapy to prevent cell death or to restore affected neurons to a normal state in PD. Preclinical studies in laboratory animals have provided several candidate neuroprotective drugs, but clinical endpoints are readily confounded by any symptomatic effect. Thus, these studies do not provide an unequivocal measure of disease progression that can be used to determine if a drug has a neuroprotective effect.

In this context emerges melatonin, an indolamine synthesized by several tissues such as the pineal gland and by extrapineal sources including macrophages, mast cells, and lymphocytes. Classically, melatonin has been considered the darkness hormone since its synthesis by the pineal gland follows the daily alternation between light and darkness. Melatonin synthesized by immune-competent cells acts in an autocrine or paracrine manner. Melatonin receptors $\left(\mathrm{MT}_{1}\right.$ and $\mathrm{MT}_{2}$ ) are expressed in numerous areas of the central nervous system (CNS). Moreover, the physiological role of melatonin is by far wider than what was considered before including learning and memory, anxiety, depression, and neuroprotection. The present review attempts to provide a comprehensive picture of the role of the melatoninergic system in CNS and to highlight recent findings showing its potential as a new palliative and neuroprotective agent in PD.

\section{Melatoninergic System}

Melatonin was isolated in 1958 by the dermatologist Lerner from 50 grams of lyophilized bovine pineal glands powder [1]. Melatonin was named after its property of lightening the skin of frogs, toads, and fishes. In these early times, Wurtman and collaborators [2] examined the distribution of $\left[{ }^{3} \mathrm{H}\right]$ melatonin in endocrine and other organs of rats and cats. They showed that iris-choroid, ovary, and periphery organs innervated by the autonomic nervous system, including the heart, take up melatonin [2]. In 1965, a paper authored by Axelrod (Nobel Prize of Medicine, 1970) et al. showed the daily variation of melatonin pineal gland content and proposed that the neural pathway that links the retina to the pineal gland involves sympathetic postganglionic fibres originated in the superior cervical ganglia [3]. In the last years, there is increasing data supporting the concept that melatonin effects are not only due to nighttime pineal gland synthesis but also triggered by melatonin synthesized by extrapineal sources $[4,5]$.

In mammals, several tissues including the pineal gland, retina [6], macrophages $[7,8]$, mast cells, lymphocytes [4], human bone marrow cells [9], astrocytes [10-12], and enterochromaffin-like cells found in the gastric mucosa [13], rat oocytes [14], placental trophoblasts [15, 16], and human colostrum phagocytes [17] synthesize melatonin. Melatonin (N-acetyl-5-methoxytryptamine) is synthesized by the acetylation of serotonin and the methylation of $\mathrm{N}$-acetylserotonin [18]. The enzymes aryl-alkyl-N-acetyltransferase (AANAT) and acetylserotonin O-methyltransferase (ASMT), also known as hydroxyl-indole-O-methyltransferase (HIOMT), are highly conserved being detected in unicellular organisms, plants, and animals [19-21].

The pineal gland is an endocrine gland of epithelial origin, as the CNS, formed by pinealocytes (modified neurons), astrocytes, and microglia [18]. Nerve fibres originate from perikarya located in the sympathetic superior cervical ganglion and the parasympathetic sphenopalatine and optic ganglion innervate the gland [22]. Sympathetic activation by darkness is the key inducer of pineal melatonin synthesis. On the other hand, the role of parasympathetic innervation is still not clear. In rats, the muscarinic receptors are present only in the developmental phase [23]. In adult rats, the only cholinergic receptors detected are nicotinic, which leads to a great entrance of calcium ions and the release of glutamate. In turn, glutamate inhibits noradrenaline-induced pinealocytes melatonin synthesis [24]. More recently, the sources and cellular effect of gamma-aminobutyric acid (GABA) were described [25]. Although the cellular and molecular mechanisms involved in the response of these neurotransmitters and hormones are becoming clear, there are little cues regarding their functional role.

In addition, the pineal gland is a circumventricular organ capable of communicating blood signals to the brain through the cerebrospinal fluid [22]. In fact, it reacts to cytokines and to circulating hormones such as glucocorticoids $[4,26]$. Proand anti-inflammatory mediators modulate pineal melatonin synthesis, adjusting the body to cope with inflammatory responses [26]. Therefore, the unbalance of pineal melatonin synthesis can predispose the organism to inflammatory and neurodegenerative diseases.

The conversion by AANAT of serotonin to $\mathrm{N}$-acetylserotonin (the immediate precursor of melatonin) in pinealocytes is the key event for the daily rhythm of melatonin. Although melatonin is the nocturnal hormone in both diurnal and nocturnal animals, the regulation of its biosynthesis is specific for each one. In diurnal animals, only the activity of the enzyme AANAT is under daily control, while in nocturnal animals both transcription and translation are induced by darkness. AANAT has a very short life span; as soon as it is synthesized, the enzyme is ubiquitinated and targeted to the proteasome, being immediately degraded. This maintains the low level of melatonin during daytime, despite the constitutive synthesis of the enzyme. Darkness transmitted to the hypothalamic suprachiasmatic nuclei by the retinohypothalamic tract activates a polysynaptic pathway, which leads to the release of noradrenaline and adenosine triphosphate (ATP) by the sympathetic nerve terminals that reach the pineal gland [18]. The transcription factor cAMP responsive element-binding (CREB) and the protein kinase $\mathrm{A}$ (PKA), activated by cyclic-AMP dependent phosphorylation upon $\beta$-adrenergic stimuli, induce the transcription of the Aanat gene and the phosphorylation of the AANAT enzyme, 
respectively [18]. The binding of phosphorylated-AANAT to the chaperone 14-3-3 impairs its entry in the proteasome and promotes the conversion of $\mathrm{N}$-acetylserotonin in melatonin by ASMT enzyme [27]. Considering the onset of darkness, the raise in plasma melatonin starts much earlier in diurnal than nocturnal animals. Therefore, in humans, it is possible to detect melatonin as soon as $1 \mathrm{~h}$ after darkness, while in rodents at least $3 \mathrm{~h}$ is necessary to detect melatonin in the plasma $[28,29]$.

In the pineal gland, ASMT is regulated by the photoperiod. In Siberian hamsters, that are strict photoperiodic animals, ASMT activity was found to be about two times higher under short photoperiods than under long photoperiods, and the peak of melatonin follows the same profile [30]. In addition, this enzyme was shown to be the limiting step of the biosynthetic pathway [31]. Therefore, while AANAT is the key enzyme for determining the circadian rhythm of melatonin, ASMT is the photoperiodic enzyme; that is, it determines the higher melatonin amplitude in the winter when compared to summer nights.

The presence of melatonin in human appendix mucosa and rat digestive tract was described around 40 years ago. After the demonstration that the enzymes responsible for melatonin synthesis are present in the gastrointestinal tract and that the content of melatonin is maintained even after pinealectomy, it was proposed that melatonin should have a local role, independent of darkness control. Melatonin synthesized in the guts is drained to the liver via hepatic portal vein and may reach concentrations 15 times higher than the blood [32]. This information need to be taken into account due to expanding knowledge regarding the relevance of the gut-brain axis in triggering and management of inflammatory based CNS diseases.

The melatonin synthesized by immune-competent cells is highly relevant for surveillance of biotic and abiotic injuries and stress, as well as for the mounting and resolution of innate immune responses. Melatonin is synthesized by lymphocytes, thymus, spleen, and bone marrow [33-36] and was shown to modify the expression of cytokines and the reactive state of T- and B-lymphocytes [4]. In the last decades, the existence of an immune-pineal axis that considers both pineal and extrapineal productions and also the physiolog$\mathrm{ical} /$ pathophysiological state of the organism was proposed [26].

In this context, the central transcription factor in defence responses, the nuclear factor kappa $\mathrm{B}(\mathrm{NF}-\kappa \mathrm{B})$, orchestrates the role of melatonin by inhibiting or activating its production by different sources [5]. The onset of an acute innate response induced by pathogen- or damage-associated molecular patterns (PAMPs and DAMPs, resp.) turns on/off the melatonin synthesis in a cell-dependent manner. Tolllike receptor 4 (TLR4) activation triggers NF- $\kappa \mathrm{B}$ nuclear translocation, decreasing melatonin synthesis in pinealocytes and inducing its production by immune-competent cells [3739]. The key event for this opposite effect lays on the NF- $\kappa \mathrm{B}$ dimer that is preferentially activated in each cell. The NF- $\kappa \mathrm{B}$ dimer translocated to the nuclei (p50/p50) in pinealocytes has no transactivating domain (TAD) and impairs Aanat transcription [40].
On the other hand, the translocation of a TAD positive NF- $\kappa$ B dimer (RelA/cRel) promotes the gene transcription in immunocompetent cells [41, 42]. The reduction of melatonin during the mounting of an innate immune response increases the expression of adhesion molecules that favour the migration of leukocytes from blood to tissues, playing a role in the inflammatory response mounting [43]. Recently, it was shown that the effect of darkness on endothelial cells primes the expression of microRNAs that negatively regulate cell adhesiveness, inflammatory response, and proliferation [44]. Melatonin synthesized by phagocytes acts in a paracrine manner favouring the phagocytosis of bacteria, fungi, parasites, and cellular debris [17, 41, 45, 46]. The synthesis of melatonin by the pineal gland is restored before the end of the acute inflammatory response, due to the inhibition of NF- $\kappa$ B by glucocorticoids released from the adrenal gland $[29,47,48]$.

Melatonin effects are mediated by high affinity $\mathrm{G}$ protein coupled receptors (GPCRs) $\mathrm{MT}_{1}$ and $\mathrm{MT}_{2}$, by nuclear receptors, and by its ability to donate electrons, acting as an antioxidant molecule [49]. The history of melatonin receptors reveals the importance of understanding the kinetic of the radioligands. Experiments with $\left[{ }^{3} \mathrm{H}\right]$-melatonin did not indicate the presence of high affinity receptors, which were revealed after the use of $\left[{ }^{125} \mathrm{I}\right]$-2-iodo-melatonin, a molecule that did not cross the plasma membrane [50]. Besides its intrinsic free-radical scavenging characteristics, the antioxidant effect of melatonin may also occur by triggering the $\mathrm{MT}_{1} / \mathrm{MT}_{2}$-dependent induction of enzymes involved in the removal of reactive oxygen and nitrogen species (ROS and RNS), a pathway that requires much lower concentrations of the ligand [4]. Melatonin receptors may also form homo- and heterodimers, increasing the complexity of its pharmacology. Melatonin $\mathrm{MT}_{2}$ receptors dimerize with serotonin $5 \mathrm{HT}_{2 \mathrm{C}}$ receptors in transfected human embryonic kidney cells (HEK 293) and human cortical cells [51]. Another interesting observation that could result in future basis for the understanding of melatoninergic drugs effects in health and disease is the dimerization of melatonin receptors with $G$ protein-coupled receptor 50 (GPR50). GPR50 shares similarity with melatonin receptors but does not bind to melatonin [52]. $\mathrm{MT}_{1}$ function is blocked by the formation of $\mathrm{MT}_{1} / \mathrm{GPR} 50$ but this effect is not observed when $\mathrm{MT}_{2}$ heterodimerizes with GPR50 [53]. Therefore, the results obtained with melatonin agonists and antagonists need to be followed by the understanding of the biology of melatonin receptors molecular complexity.

\section{Melatoninergic System and Neuroprotection}

Neuroprotective mechanisms preserve neuronal structure and function against acute or chronic insults of the CNS. Abrupt changes in brain irrigation by trauma or ischemia or the presence of neurotoxins demand immediate reactions of the nervous system cells. Deleterious effects triggered by endogenous molecules or by dysfunctional processes are the basis of neurodegenerative diseases and brain tumors. Inflammatory changes, ROS and RNS formation, mitochondrial dysfunction, excitotoxicity, apoptosis, and protein 
aggregation are processes commonly found in these cases and related to neuron injuries [54].

Neuroprotective melatonin effects were shown at the molecular, cellular, and tissue level in animal models and in human trials conducted in patients with different CNS diseases. Reduction of inflammatory mediators, apoptosis, and unbalance of redox state are involved in the neuroprotection induced by melatonin [21, 55-57].

Several studies describe antioxidant effects of melatonin $[58,59]$. Indeed, these protective effects are achieved by direct scavenger mechanisms or by melatonin receptorsmediated pathways. Melatonin and the metabolites N1acetyl-5-methoxykynuramine (AMK) and N1-acetyl-N2formyl-5-methoxykynuramine (AFMK) are electron donors and scavenge hydroxyl radicals, hydrogen peroxides, and singlet oxygen in a stoichiometric manner [60]. Activation of melatonin $\mathrm{MT}_{1}$ and $\mathrm{MT}_{2}$ receptors also exerts protective effects, in part dependent on the control of antioxidant enzymes expression such as glutathione peroxidase, glutathione reductase, and superoxide dismutase [61, 62].

The pivotal pathway for triggering inflammatory responses is the uncontrolled activation of the nuclear translocation of NF- $\kappa \mathrm{B}$ dimers by PAMPs or DAMPs, promoting neuronal death [37]. Melatonin inhibits the nuclear translocation of NF- $\kappa \mathrm{B}$ in several cellular models. Furthermore, melatonin exerts a protective effect by blocking NF- $\kappa \mathrm{B}$ activation induced by lipopolysaccharide (LPS) in both rats and cells $[63,64]$. NF- $\kappa \mathrm{B}$ inhibitors block either the melatonin-induced neuroprotective or neurorestorative effects. Melatonin also inhibits other signalling pathways linked to innate immune responses, as nucleotide-binding oligomerization domain-like receptor family (NLR) pyrine domain-containing 3 (NLRP3) [65, 66]. This receptor located in the inflammasome upregulates apoptotic signalling pathways in the brain and peripheral inflammatory responses. Thus, melatonin impairs the activation of important signalling pathways that are responsible for triggering innate immune response. In the context of the immune-pineal axis, that activation of NF- $\kappa \mathrm{B}$ initially inhibits the synthesis of melatonin by the pineal gland, favouring the mounting of the inflammatory response, and as the response progresses, it induces the synthesis of melatonin by microglia $[5,64]$.

Another interesting link between melatoninergic system and brain inflammatory responses is the regulation of the alpha-7-nicotinic acetylcholine receptors $(\alpha 7 \mathrm{nAchR})$ by melatonin [54, 67-69]. Cholinergic control of inflammation adjusts the intensity of appropriate immune responses and $\alpha 7$ nAchR activation in immunocompetent cells shifts the immune responses towards a more anti-inflammatory profile. The expression and the functional response of $\alpha 7 \mathrm{nAchR}$ located in the sympathetic neurons terminal present a daily variation dependent on the circadian rhythm of melatonin. Moreover, melatonin favours $\alpha 7 \mathrm{nAchR}$ expression in the plasma membrane, reducing the desensitization due to internalization [68]. Therefore, melatonin improves $\alpha 7 \mathrm{nAchR}-$ dependent cholinergic activities. Indeed, melatonin protects neurons from prion-mediated mitochondrial neurotoxicity by increasing the $\alpha 7 \mathrm{nAchR}$-mediated autophagic flux [54] and ischemic neurons survival by increasing the heme oxygenase-1 (HO-1) expression [69]. Furthermore, melatonin ameliorates cholinergic dysfunction and avoids neuronal apoptosis in the APP 695 transgenic mouse model of AD [67].

Interestingly, neurodegenerative disorders such as $\mathrm{AD}$ and $\mathrm{PD}$ are associated with impaired brain expression of both melatonin and $\alpha 7 \mathrm{nAchR}$ [70-73] and disruption of nocturnal melatonin rhythm [74-76]. It is noteworthy that amyloid $\beta$ (A $\beta$ ) peptides inhibit the synthesis of melatonin in rat pineal gland by activating NF- $\kappa \mathrm{B}$ [77] and that melatonin treatment improves cognition and sleep in $\mathrm{AD}$ patients [78]. Long-term melatonin treatment induces receptor-dependent and receptors-independent neuroprotective effects in animal model of AD [62]. Receptor-independent effects of melatonin were observed on nonspatial cognitive performance, reduction of cortical and hippocampal amyloid plaques, and plasma $\mathrm{A} \beta_{1-42}$ levels. On the other hand, melatonin receptordependent effects were observed on spatial learning and memory and on the modulation of antioxidant enzymes [62]. Melatonin also attenuated $\mathrm{A} \beta$-induced neurofilament hyperphosphorylation [55] and neuroinflammation [79]. Finally, melatonin restored mitochondrial function in a mouse model of $\mathrm{AD}$ via activation of melatonin receptors [56].

Disruption of melatoninergic system in diverse neurodegenerative diseases reinforces the potential neuroprotective effects of melatonin. Huntington's disease (HD) patients present a rhythm delay in nocturnal melatonin production [80]. The clinical relapses in multiple sclerosis are negatively correlated with melatonin levels [81] and no melatonin nocturnal peak is detected in $\mathrm{AD}$ [74] and stroke [82] patients. Interestingly, the reduction on nocturnal melatonin production occurs in early stages of $\mathrm{AD}$ [75]. Low night levels of melatonin are also commonly reported in schizophrenia patients [83].

The great exception is $\mathrm{PD}$, which shows some controversies in the literature. Some reports refer no alteration [84, 85], small phase alterations [86], or decreased production of melatonin [87]. Nevertheless, Videnovic and colleagues [87] showed that, besides the reduction of circadian melatonin levels in PD, those patients with excessive daytime sleepiness present an even lower production of the hormone. Moreover, nocturnal working was shown to reduce the risk of PD while long daytime sleep was associated with increased occurrence of PD [88, 89].

Alongside the impaired production of melatonin, some neurodegenerative diseases also present altered expression of melatonin receptors. In PD patients, the expression of both $\mathrm{MT}_{1}$ and $\mathrm{MT}_{2}$ receptors is reduced in the amygdala and $\mathrm{SNc}$ [73]. Studies conducted in brains tissues of $\mathrm{AD}$ patients showed decreased expression of $\mathrm{MT}_{1}$ and $\mathrm{MT}_{2}$ in the cortex and in the pineal gland [71], $\mathrm{MT}_{1}$ reduction in the suprachiasmatic nucleus [72], and a dual modulation in the hippocampus characterized by increased expression of $\mathrm{MT}_{1}$ and decreased expression of $\mathrm{MT}_{2}$ [70]. In addition, $\beta$ amyloid directly binds to $\mathrm{MT}_{1}$ and $\mathrm{MT}_{2}$ receptors, decreasing $\mathrm{MT}_{1}$ binding sites and the activation of downstream pathways triggered by both melatonin receptors subtypes [77].

Finally, it is important to consider the role of extrapineal melatonin synthesized within the CNS as a resilience 
mechanism against neurodegenerative processes. There are some important considerations regarding how melatonin reaches the CNS, the different capability of each brain area to synthesize melatonin under stressful conditions, and the relevance of melatonin metabolism inside the brain. Although i.p. administration of melatonin may reach the brain [90], daily circadian rhythm of melatonin in the cerebrospinal fluid is due to direct influx of melatonin from the pineal gland (i.e., independent of the plasma concentration) [9193]. Acute injuries activate the immune-pineal axis blocking melatonin synthesis by the pineal gland and inducing it by immune-competent cells located in the injured area $[5,26]$. Injection of LPS in the third ventricle increases AANAT expression in cortex, hippocampus, and cerebellum but induces melatonin synthesis only in the cerebellum [64]. This effect is mediated by the activation of NF- $\kappa \mathrm{B}$ pathway and it was observed that cerebellar, but not cortical and hippocampal, neurons present reduced number of neuronal deaths after LPS injection. However, when LPS was given after the blockade of melatonin $\mathrm{MT}_{1} / \mathrm{MT}_{2}$ receptors with the nonselective competitive antagonist luzindole, there was a significant increase in cerebellar neuronal death.

Therefore, this review will assess the role of melatoninergic system in PD, focusing on the antioxidant, antiinflammatory, motor, and nonmotor effects of melatonin. Besides the protective effects of melatonin described in the next sessions, a question that still has no answer is whether a putative local production of melatonin by some patients would explain the contradictory observations aforementioned regarding the nocturnal melatonin production in $\mathrm{PD}$ patients.

\section{Parkinson's Disease}

PD is characterized by a slow and progressive loss of DAergic neurons in the $\mathrm{SNc}$, an important pathway for fine modulation of motor function [94]. The first report of PD is dated in 1817 in the James Parkinson's monograph "An Essay on the Shaking Palsy." Symptoms observed by Parkinson were described as "involuntary tremulous motion with lessened muscular power, in parts not in action even when supported, with a propensity to bend the trunk forward and to pass from walking to a running pace" [95]. Since then, PD is known as a movement disorder that mainly affects people of middle to old age [96].

$\mathrm{PD}$ is highly linked with the aging, being responsible for a significant increase in morbidity and mortality, affecting the social and economic life of individuals and society [57, 97]. According to the United Nations, it is believed that the number of elderly people in the world will reach 2 billion in 2050. Due to this, the World Health Organization (WHO) accounts that the number of cases of PD tends to increase and the importance of the disease as a public health problem will become even more significant. Additionally, PD is more common in males, with a ratio of men to women of $3: 2$ [98].

Although the symptoms and the neuropathology of PD have been well characterized, the mechanisms and causes of the disease remain unclear. Therefore, PD is described as a multifactorial disease that could be influenced by age and genetic and environmental factors [99-101]. PD is responsible for a significant increase in morbidity and mortality, affecting the social and economic life of individuals and society [57, 97].

The environmental hypothesis of PD aetiology is based on epidemiological studies showing the high frequency of the disease in individuals exposure to xenobiotics such as agricultural chemicals (pesticides, herbicides, etc.) and heavy metals (iron, manganese, aluminium, etc.) [102]. Other hypotheses of PD aetiology include genetic factors, natural aging process, increase of the formation of reactive species or inadequate functioning of its neutralizing mechanisms, and reduction of ATP stores that end up leading to neuronal death [103].

The majority of cases (90-95\% of cases) are idiopathic, affecting $5 \%$ of population over 85 years old. However, in $5-10 \%$ of cases, PD can have a genetic component showing recessive and/or dominant modes of inheritance. Several genes mutations have been identified resulting in PD. Early onset PD or familial PD (occurring in people under 50 years of age) is less common, and recent data has identified some nuclear genes associated with familial PD, like $L R R K 2$, PARK2, SNCA, PARK7, and PINK1 [104].

Despite the knowledge derived from genetic research in $\mathrm{PD}$, the accurate mechanism underlying the DAergic loss in PD is still not understood. However, mitochondrial dysfunction and oxidative stress in which there is an increase of the production of ROS, abnormal protein handling, neuroinflammation, excitotoxicity, and apoptotic processes have a central role in PD pathogenesis [101,103].

The neuron's environment is a main contributor to neurodegeneration. Many evidences suggest that neurodegeneration can occur because of a cascade of events that affects the neuron's environment, called neuroinflammation [105]. Neuroinflammatory mechanisms involved in $\mathrm{PD}$ pathogenesis comprise microglial activation, astrogliosis, and lymphocytic infiltration and also involve alterations in the morphology of glial cells, including both astrocytes and microglia, indicating their interactions with the alterations in the homeostasis of the environment $[101,105]$. Neurodegeneration in PD may be accompanied by an inflammatory reaction, characterized by activation of microglia, which leads to production of a number of inflammatory mediators (e.g., NF- $\kappa \mathrm{B}$, interleukin1 (IL-1), IL-6, IL-1 $\beta$, cyclooxygenase-2 (COX-2), tumoral necrosis factor- $\alpha$ (TNF- $\alpha$ ), inducible nitric oxide synthase (iNOS), interferon- $\gamma$ ) and increased expression of different proinflammatory cytokines by glial cells. Besides, an increase in the level of these components in the substantia nigra and in the cerebrospinal fluid (CSF) and an elevation of $\gamma / \delta+$ $\mathrm{T}$ cells in the peripheral blood and CSF of patients with PD were also reported [101, 106, 107]. This increase in the proinflammatory cytokine levels could switch on different apoptotic pathways involved in the degeneration of DAergic neurons [94]. Taken together, oxidative stress, accumulation of endogenous cell metabolism products, excitotoxins like glutamate, toxic proteins, and a decrease of trophic factors can lead to apoptotic events of neurodegeneration $[108,109]$.

Oxidative stress also plays a pivotal role in DAergic neurodegeneration in $\mathrm{PD}$. The DAergic neurons themselves seem 
to contribute to ROS production through DA metabolism, which produces superoxide anion, hydroxyl radical, and hydrogen peroxide. Furthermore, the autoxidation of DA produces DA-quinone, a molecule that can damage the proteins structure [109].

Reactive species are involved in the protein aggregation. In $\mathrm{PD}$, the presence of $\alpha$-synuclein and ubiquitin aggregates in neurons in processes of degeneration is observed, especially in the DAergic neurons from SNc. These aggregates, known as Lewy bodies, are pathological markers for PD, being found in $85 \%$ of autopsies of PD patients [110, 111].

$\alpha$-Synuclein plays an important role in synapse maturation and maintenance of neurons and its expression is developmentally regulated, redistributing from the cell bodies to synaptic terminals during periods of neuronal differentiation [112]. Also, this protein is upregulated during periods of synaptic plasticity [112]. Studies suggest that the $\alpha$-synuclein can regulate the function of the two key proteins that control the amount of DA inside nerve terminals, regulating the uptake of extracellular DA by the DA transporter (DAT) and the packaging of cytosolic DA by the vesicular monoamine transporter 2 (VMAT2) [112]. Thus, the aggregation of $\alpha$ synuclein triggers cellular mechanisms that lead to progressive death of DAergic neurons [113].

Many environmental toxicants, in particular pesticides, have been considered risk factors for PD. There are many studies evaluating the influence of exposure to heavy metals, solvents, and carbon monoxide in PD development $[99,114$, 115]. Epidemiological studies have pointed a clear association between increased PD risk and specific environmental factors such as rural residence, drinking water from wells, and exposure to agricultural chemicals, including paraquat, rotenone, maneb, dieldrin, fungicides, and organochlorines $[99,102,116,117]$.

The degeneration of DAergic neurons in PD occurs mainly in the basal ganglia, a group of subcortical nuclei that control the voluntary movements (besides many other functions including procedural memory processing). The basal ganglia is composed of the striatum (putamen and caudate), globus pallidus externa and interna, subthalamic nucleus, $\mathrm{SNc}$, and the substantia nigra pars reticulata $(\mathrm{SNr})$. The basal ganglia forms neural loops extending from motor cortex to the motor thalamus and back to the cortex, and these loops seem to control the movements at a varying level of complexity [96]. The degeneration of DAergic neurons in PD occurs mainly in the nigrostriatal pathway and in minor extension in the ventral tegmental area [96].

Motor symptoms of PD begin to manifest when approximately $70 \%$ of DAergic neurons in the nigrostriatal pathway have been lost. In the beginning of the disease, the motor symptoms can be unnoticed or misinterpreted for a long time. Fatigue, lugubrious stiff face, impairment in the quality of speech, and extreme slowing down can be the first signals of PD and sometimes they can be confused with other diseases or with the aging itself [104]. The classical motor symptoms of PD include resting tremor, bradykinesia, muscular rigidity, and postural imbalance [118].

Additionally, a growing body of evidence demonstrates that PD patients commonly present sleep disturbances [87,
TABle 1: Drugs used for symptomatic treatment of Parkinson's disease.

\begin{tabular}{ll}
\hline Drug & Mechanism of action \\
\hline L-DOPA & $\begin{array}{l}\text { DA precursor } \\
\text { DA precursor + peripheral } \\
\text { dopa-decarboxylase } \\
\text { inhibitor } \\
\text { carbidopa }\end{array}$ \\
$\begin{array}{l}\text { Bromocriptine, pergolide, } \\
\text { pramipexole, ropinirole }\end{array}$ & DA receptor agonists \\
Selegiline, rasagiline & $\begin{array}{l}\text { Monoamine oxidase B } \\
\text { inhibitors }\end{array}$ \\
Ancrease of DA release and \\
glutamate NMDA receptor \\
antagonist \\
Muscarinic receptor \\
Trihexyphenidyl, benztropine & $\begin{array}{l}\text { antagonists } \\
\text { Catechol-O- } \\
\text { methyltransferase } \\
\text { inhibitors }\end{array}$ \\
\end{tabular}

Adapted from [108].

$119,120]$, since DA is a neurotransmitter of major importance for the circadian cycle. Sleep disturbances are among the most common nonmotor symptoms of $\mathrm{PD}$, affecting about $90 \%$ of $\mathrm{PD}$ patients. Impaired circadian function in PD is related not only to the disruption of sleep-wake cycle, but also to other functions such as autonomic imbalance, cognitive decline, and psychiatric disorders $[121,122]$.

Nowadays, it is well known that other neurotransmitter systems (e.g., cholinergic, noradrenergic, and serotonergic) also degenerate in PD, and the cell loss is extended to other brain regions besides the nigrostriatal pathway. This nonDAergic degeneration is a major cause of the nonmotor symptoms of PD such as cognitive decline, mood disorders, and autonomic dysfunctions. Nonmotor symptoms of PD are present across all the disease stages, but the frequency and severity increase with disease progression. Many studies have shown that these symptoms are highly incapacitating and have a major impact on the quality of life ahead of motor symptoms [123].

Besides the sleep disturbances, nonmotor symptoms of PD also include cognitive decline, depression, and anxiety $[124,125]$. Most of studies demonstrated that the psychiatric symptoms are related to monoaminergic deficits within components of the limbic system implicated in emotional and affective functions [125]. As demonstrated by Braak et al. [126], the progressive death of DAergic neurons in PD occurs alongside the degeneration of noradrenergic and serotonergic systems.

The current available drugs for PD (see Table 1) mainly improve motor symptoms, without preventing the progression of the disease. Besides, the available treatments can cause several motor complications following chronic use [127] and eventually these treatments present low efficacy [128].

The most effective treatment for PD involves DA replacement therapy, made by the administration of its precursor 3,4-dihydroxy-L-phenylalanine (L-DOPA) associated with dopa-decarboxylase inhibitors (benserazide or carbidopa). 


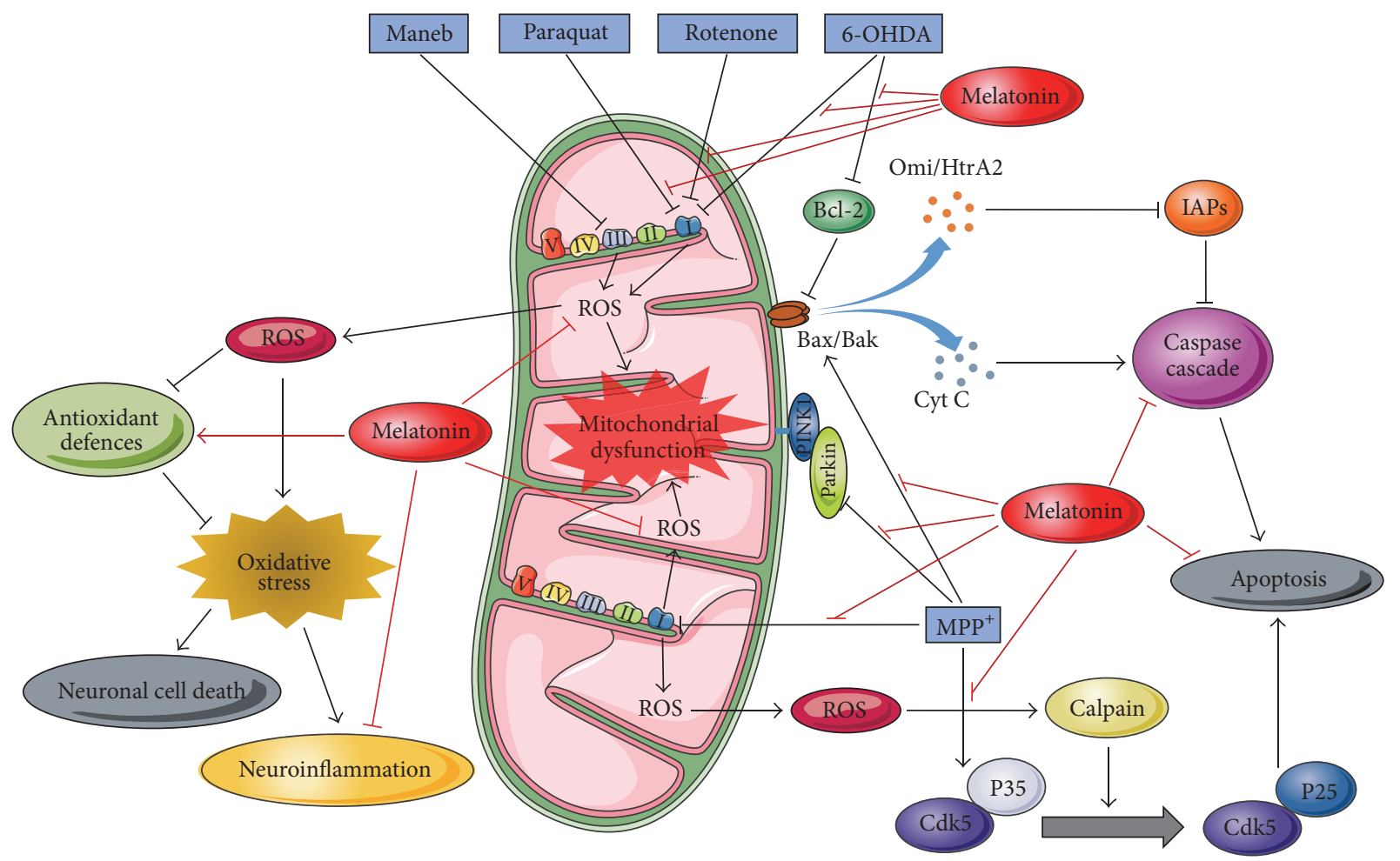

FIGURE 1: Summary of molecular mechanisms associated with neuroprotective effects of melatonin in in vivo and in vitro models of Parkinson's disease. The main molecular mechanism of neurotoxins is related to its ability to inhibit the complexes of the mitochondrial electron transport chain. The inhibition of these complexes leads to an increased production of reactive oxygen species (ROS) and, consequently, to mitochondrial dysfunction, oxidative stress, activation of apoptotic pathways, and neuroinflammation, culminating in neuronal cell death. Melatonin exerts neuroprotective effects through different mechanisms: protection of the complex I activity, neutralization of ROS, increased cell antioxidant defences, reducing neuroinflammation, inhibition of caspases cascade, and cellular apoptosis. Melatonin is also able to protect against induction of Bax and Cdk5/p35 expression and inhibition of Parkin/PINK1 and Bcl-2 expression induced by toxins in PD models. 6-OHDA: 6-hydroxydopamine; Bak: Bcl2 antagonist/killer; Bax: Bcl2 associated X; Bcl2: B cell leukemia/lymphoma 2; Cdk5: cyclindependent kinase 5; Cyt C: Cytochrome C; IAPs: inhibitors of apoptosis proteins; $\mathrm{MPP}^{+}$: 1-methyl-4-phenylpyridinium; Omi/HtrA2: HtrA serine peptidase 2; ROS: reactive oxygen species.

Although such treatment improves motor symptoms of PD, the long-term treatment with L-DOPA is inefficient and causes numerous complications [129].

Aside from the treatment with L-DOPA, there are new treatment strategies focusing on the constant stimulation of the DAergic system, for example, the use of drugs with longer half-lives such as the DA receptor agonists ropinirole and pramipexole that allows the later use of L-DOPA or other drugs with short half-life $[100,130]$. Table 1 summarizes the drugs available for symptomatic treatment of PD.

Despite all these options for PD treatment, none of these drugs prevent the disease progression. Therefore, there is a need to develop drugs or interventions that prevent or slow the progression of the degeneration of DAergic and nonDAergic neurons in PD.

\section{Neuroprotective Potential of Melatoninergic System in Parkinson's Disease}

Several studies have shown that PD patients exhibit changes in the melatonin production and in the expression of melatoninergic receptors $\mathrm{MT}_{1}$ and $\mathrm{MT}_{2}$ in the $\mathrm{SNc}[73,84-$ 87]. This reduction in endogenous melatonin production in PD patients, along with the discovery of the antioxidant activity of melatonin, has led to increasing interest in affording neuroprotection in PD. In this regard, it is known that the CNS is highly vulnerable to the effects of ROS, mainly due to high consumption of oxygen from this tissue, and that oxidative stress has a significant importance in the pathogenesis of PD [183].

Diverse neurotoxins have been used to mimic behavioural and neurochemical characteristics of PD in laboratory animals and thereby improve the knowledge about the pathogenesis and molecular mechanisms of the disease (Figure 1). These neurotoxins-based models are also useful for the screening of potential new treatments, including new agents aiming neuroprotection [184]. In this context, exogenous melatonin administration has demonstrated an outstanding neuroprotective effect in animal models of PD induced by different toxins such as 6hydroxydopamine (6-OHDA), 1-methyl-4-phenyl,1-1,2,3,6tetrahydropyridine (MPTP), rotenone, paraquat, and maneb (Table 2) $[132,144,161,164]$. 


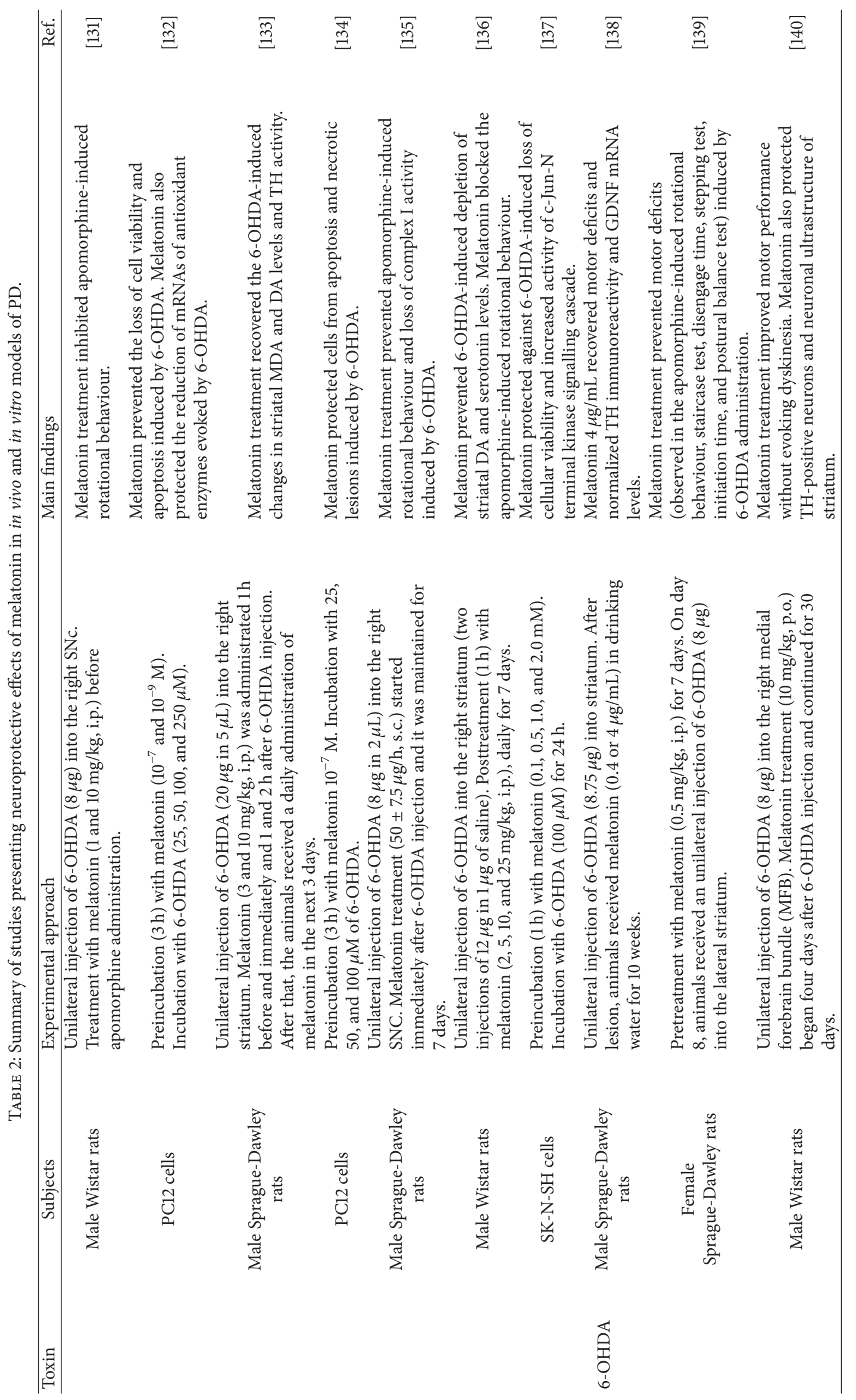




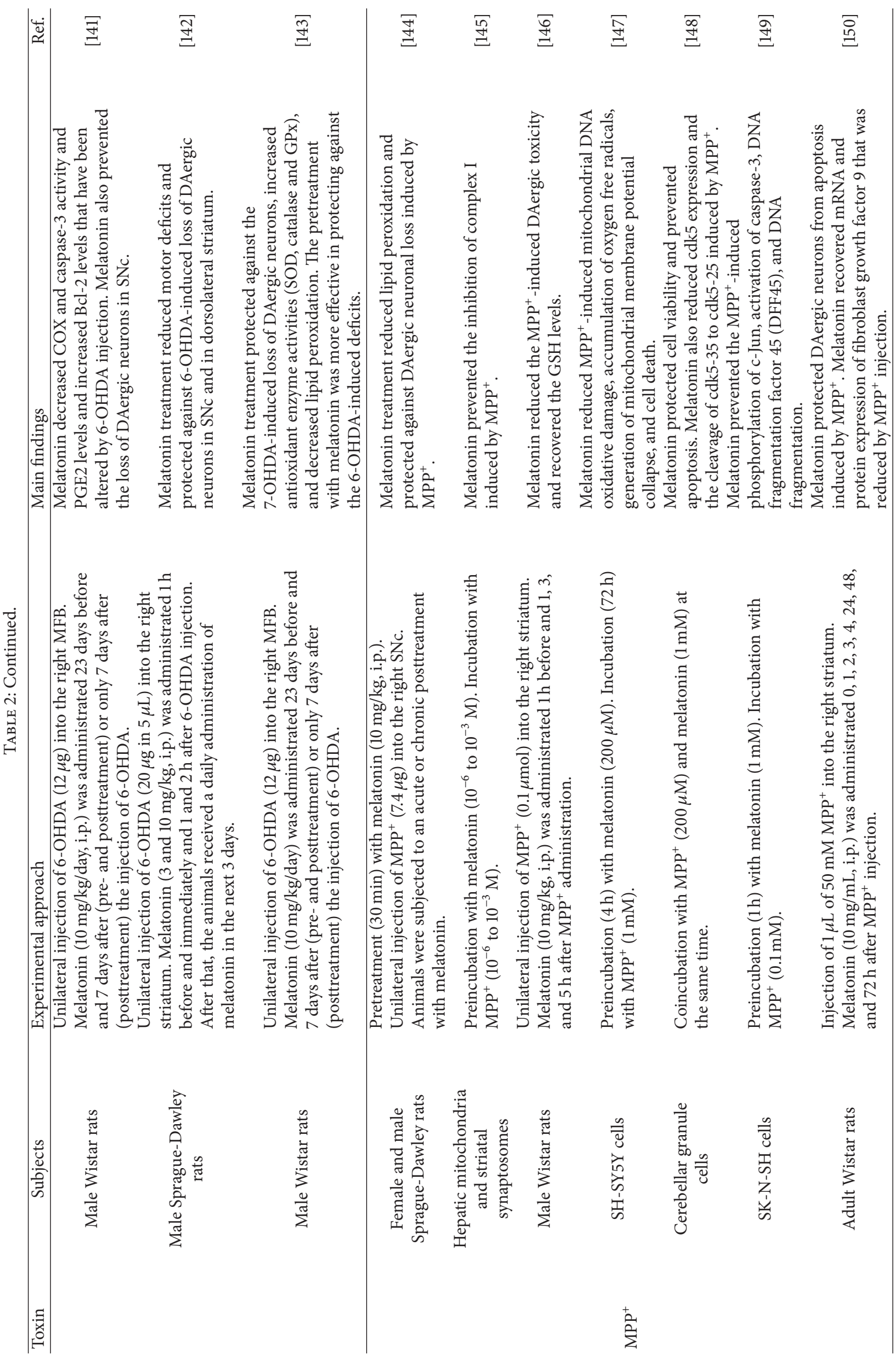




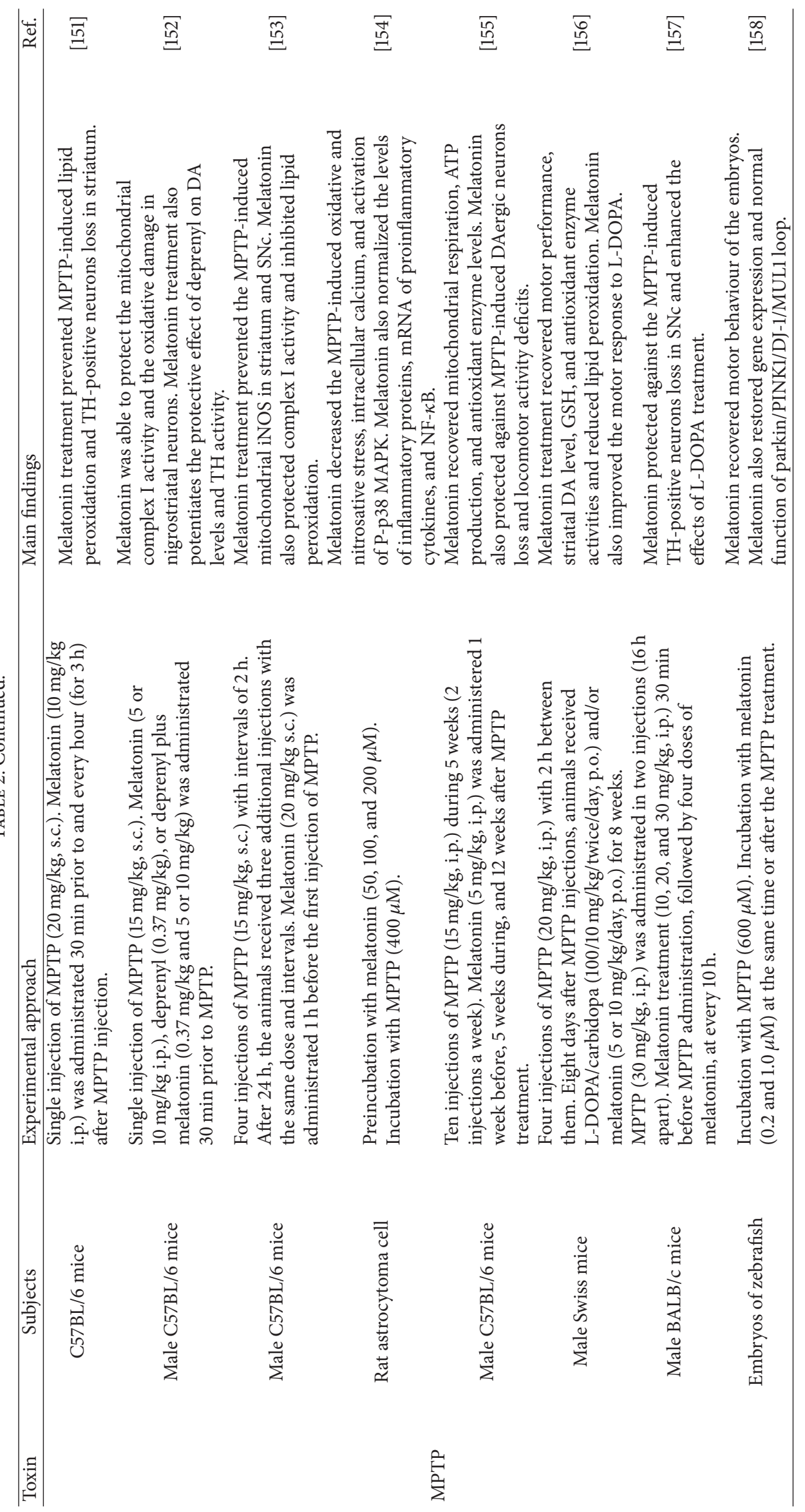




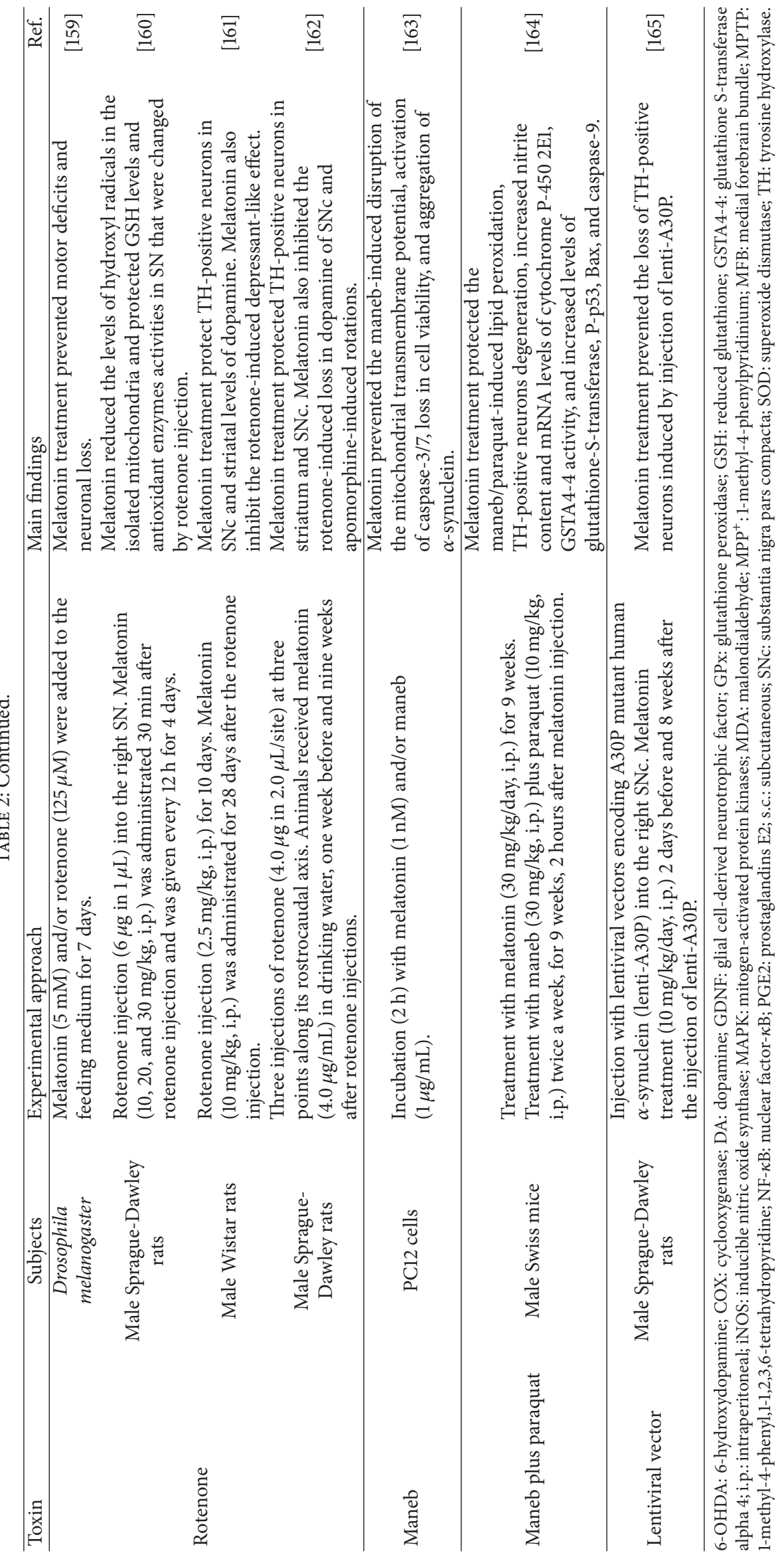


6-OHDA was the first toxin used to model the DAergic neurodegeneration similar to that seen in PD [185]. In DAergic neurons, 6-OHDA is internalized via DAT, reaching the interior of the cell where it will elicit its toxic effects [186]. The 6-OHDA exerts its toxicity mainly through two mechanisms: (1) autooxidation and (2) the inhibition of complexes I and IV of the mitochondrial electron transport chain. These mechanisms increase ROS production, which can induce neuroinflammation, microglial activation, and induction of apoptotic pathways culminating in cell death [186].

Unilateral nigrostriatal lesions induced by 6-OHDA followed by challenge with DA receptor agonists (e.g., apomorphine) lead to rotational behaviour in these animals; the rotational behaviour is mainly caused by the increased sensitivity to DA as a consequence of upregulation of DA receptors, in response to the reduced release of this neurotransmitter in the striatum [187]. Melatonin treatment confers DAergic neuroprotection through the normalization of oxidative unbalance generated by 6-OHDA administration, which was characterized by the measurement of expression and activity of antioxidant enzymes and levels of lipid peroxidation $[132,133,143]$. This effect may be due to the ability of melatonin to neutralize reactive species [188] or by the melatonin-induced increased activity [143] and expression of antioxidant enzymes [132]. Furthermore, Dabbeni-Sala et al. [135] demonstrated that melatonin is able to protect the 6-OHDA-induced inhibition of complex I activity of the mitochondrial electron transport chain in mice. In addition, melatonin also led to c-Jun phosphorylation inhibition, increased Bcl-2 levels, and decreased caspase-3 activity, blocking the apoptosis induced by 6 -OHDA $[132,134$, 137, 141] (Table 2).

The anti-inflammatory effect of melatonin was also observed in 6-OHDA model of PD. Melatonin inhibited COX enzyme activity and reduced the prostaglandin E2 levels (PGE2) [141]. Of high importance is the notion that the potential neuroprotective effects of melatonin in $\mathrm{PD}$ were demonstrated by independent research groups, where melatonin protected against the 6-OHDA-induced loss of tyrosine hydroxylase (TH) positive neurons in the SNc and striatal projections accompanied by significant improvement of motor impairments in rodents $[131,135,136]$ (Table 2).

MPTP is another toxin widely used to mimic PD in animal models. This toxin was first described by Langston et al. [189] after causing a permanent Parkinsonism in drug users of northwestern California. The MPTP was accidentally produced during the synthesis of 1-methyl-4phenyl-4-propion piperidine (MPPP). After administration, MPTP crosses the blood-brain barrier and is converted into the active toxin 1-methyl-4-phenylpyridinium $\left(\mathrm{MPP}^{+}\right)$by the enzyme monoamine oxidase $\mathrm{B}$ (MAO-B) present on glial cells. $\mathrm{MPP}^{+}$has high selectivity for DAergic neurons since it is internalized by the DAT present in these cells. Inside the cell, $\mathrm{MPP}^{+}$inhibits the activity of complex I of the mitochondrial electron transport chain, causing an increase in the production of free radicals. This effect leads to activation of apoptotic pathways and consequent death of DAergic neurons [190]. MPTP studies often use systemic administration of this toxin or infusion of $\mathrm{MPP}^{+}$directly into the target structure, because $\mathrm{MPP}^{+}$does not cross the bloodbrain barrier. Melatonin treatment prevented the loss of THpositive neurons in the SNc at the same time which improved motor deficits induced by MPTP $[144,151]$. Furthermore, melatonin, when coadministered with L-DOPA, was able to improve the motor benefits induced by L-DOPA [157] (Table 2).

The neuroprotective effect of melatonin seems to be mainly related to the its antioxidant activity, promoting reduced levels of lipid peroxidation, free radicals, oxidative damage in the mitochondrial DNA, and protection of the levels of GSH and antioxidant enzymes activity that are impaired by MPTP/MPP ${ }^{+}$administration [147, 151, 153, 155, 156] (Figure 1). Further, Khaldy et al. [191] showed that melatonin was able to prevent hydroxyl radical generation evoked by DA autoxidation evaluated in vitro. The mechanisms of melatonin neuroprotection (summarized in Figure 1) were investigated in in vitro and in vivo studies.

Some other mechanisms of melatonin neuroprotection have been demonstrated. Neurotrophic factors are important for the development, maintenance, and function of neurons and glial cells [192]. Glial cell line-derived neurotrophic factor (GDNF) is a neurotrophin known to promote the survival of DAergic neurons. GDNF expression was increased in rat C6 glioma cells exposed to melatonin [193]. The C17.2 neural stem cell line expresses $\mathrm{MT}_{1}$ receptors and melatonin was also shown to increase GDNF expression in these cells [194]. Systemic MPTP administration in rats during 7 days decreased DA levels and increased GDNF mRNA expression in the striatum, while intrastriatal injections of melatonin further enhanced GDNF mRNA expression in this brain structure [195].

Another important neurotrophin that has potent effect in the survival and morphology of DAergic neurons is the brain-derived neurotrophic factor (BDNF) [196]. Howells and colleagues showed that BDNF expression is reduced in the SNc of PD patients [196]. However, nM concentrations of melatonin were shown to increase BDNF levels and exert neuroprotective effect in $\mathrm{MT}_{2}$-knockout mice and in mouse cerebellar granule cells that underwent low-potassium toxic insults [197]. Rats tested under sleep deprivation and treated with melatonin also showed increased levels of BDNF in the cerebral cortex and hippocampus [198]. In addition, BDNF mRNA levels were increased in rat hippocampus and prefrontal cortex after acute administration of the $\mathrm{MT}_{1} / \mathrm{MT}_{2}$ agonist agomelatine [199]. Therefore, the regulation of the expression of neurotrophic factors by melatonin is likely part of the mechanism of neuroprotection exerted by melatonin.

Given the importance of $\alpha$-synuclein alterations in PD, some studies have focused on the effect of melatonin in $\alpha$ synuclein expression and aggregation. In vitro studies showed that melatonin protects dopaminergic cells such as SK-N-SH from the neurotoxicity induced by amphetamine (AMPH) and prevents the toxic overexpression of $\alpha$-synuclein that occurs when these cells are exposed to AMPH [110, 200]. In this cell model, the AMPH increases $\alpha$-synuclein expression while reducing $\mathrm{TH}$ phosphorylation, which is necessary for $\mathrm{TH}$ activation and DA synthesis [200]. An in vivo study by 
Sae-Ung et al. [201] revealed that subcutaneous injections of AMPH in rats significantly increased $\alpha$-synuclein levels in the $\mathrm{SNc}$, nucleus accumbens, striatum, and prefrontal cortex. However, the concomitant administration of AMPH and melatonin drastically reduced $\alpha$-synuclein accumulation [201]. In a model of kainic acid-induced neurotoxicity in C57BL/6 mice, the hippocampal $\alpha$-synuclein aggregation was reduced by the oral administration of melatonin $1 \mathrm{~h}$ prior to kainic acid injection [202]. Taken together, these results demonstrate the potential of melatonin to modulate $\alpha$-synuclein expression and protect DAergic cells against its undesirable toxic alterations (Table 2).

Melatonin also has a protective effect on the mitochondria, preventing the MPTP-induced inhibition of the complex I activity of the electron transport chain and the stimulation of iNOS activity, avoiding the potential collapse of mitochondrial membrane triggered by MPTP $[145,147$, 153]. Neuroinflammation evoked by MPTP administration, characterized by increased levels of inflammatory proteins, mRNA proinflammatory cytokines, and NF- $\kappa \mathrm{B}$, was also attenuated by melatonin treatment [154] (Table 2).

The mechanism of MPTP toxicity appears to involve the stimulation of the phosphorylation of p38-MAPK, increasing the cdk5-35 expression and its cleavage to cdk5-25, which are involved in neurodegeneration $[148,154]$. The administration of $\mathrm{MPTP} / \mathrm{MPP}^{+}$also leads to a reduction in the mRNA and expression of fibroblast growth factor 9 (FGF9), which participates in the proliferation, differentiation, and survival of the cell. The expression and function of parkin/PINK1/DJ1/MUL1 loop, which plays an important role in maintaining mitochondrial homeostasis, are also altered by this toxin $[150,158]$. All these changes were normalized by melatonin treatment $[148,150,154,158]$ (Table 2).

As described before, epidemiological studies have shown that exposure to certain pesticides increases the risk of developing PD and this has led to a growing interest in the development of animal models using environmental toxins such as rotenone, paraquat, and maneb [203]. Rotenone can exert its toxic effects by inhibiting the activity of complex I of the electron transport chain in mitochondria, leading to generation of ROS. Similar to MPTP, rotenone can be administered systemically or directly into the target brain structure of rodents and in cell cultures [186]. Melatonin has a protective effect against neurodegeneration caused by rotenone in different experimental protocols. Melatonin treatment reduced oxidative stress caused by rotenone, which was evidenced by reduced levels of hydroxyl radicals in the mitochondria, protection of GSH levels, and activity of antioxidant enzymes [160]. Melatonin also inhibited apoptosis induced by rotenone by reducing the Bax expression and release of Omi/HtrA2 [204]. This neuroprotective effect of melatonin culminated in the prevention of motor deficits evoked by rotenone administration in rodents and in a Parkinsonism model in Drosophila melanogaster $[159,161,162]$ (Table 2).

Maneb and paraquat are pesticides used to mimic PD in cells and animals and they can be administered alone or in combination, which increases their toxicity. Paraquat and maneb can inhibit the biosynthesis of ATP and induce the formation of ROS by inhibiting the activity of complexes
I and III of the mitochondrial electron transport chain, respectively [186]. Melatonin showed neuroprotective effect against toxicity induced by these pesticides through inhibition of oxidative stress and apoptotic pathways $[163,164]$. In addition, melatonin was able to inhibit the aggregation of $\alpha$ synuclein in P12 cells exposed to maneb [163] (Table 2).

In summary, melatonin demonstrated neuroprotective effects in different experimental models of PD. This neuroprotection seems to be mainly dependent on the modulation of the redox state of the cell by the melatonin [133, 143, $144,147,151,153,164]$. However, the models currently used to mimic the PD have limitations and do not accurately correspond to the disease in humans. In addition, the adverse effects of chronic administration of melatonin are still poorly understood. Thus, further studies using genetic models of $\mathrm{PD}$ are necessary to confirm the neuroprotective potential of melatonin in the disease.

\section{Melatoninergic System as a Putative Target for Treating Motor and Nonmotor Symptoms of Parkinson's Disease}

6.1. Motor Symptoms. Many studies have assessed the possible role of melatonin in the modulation of motor symptoms of PD with discrepant findings [205]. The majority of studies showing the benefits of melatonin on evoked motor deficits in animal models of PD performed a pretreatment with melatonin. In such studies, melatonin exerts neuroprotective effects by preventing the death of DAergic neurons in the SNc and thus avoiding the development of motor dysfunction. However, Gutierrez-Valdez et al. [140] employed a different protocol where rats underwent a unilateral injection of 6OHDA into the medial forebrain bundle and were treated with melatonin or L-DOPA, 4 days after the injury. Abnormal irregular movements (AIMs) evaluation, and the beam walking test were performed to assess dyskinesia and motor function. Melatonin was able to improve the rats walking ability without inducing the onset of AIMs, as in the case of L-DOPA treatment. Furthermore, melatonin treatment attenuated the loss of TH-positive neurons and protected the ultrastructural preservation of striatal neurons. These results suggest that although melatonin treatment started 4 days after the lesion, the beneficial effects on the motor symptoms were maintained. Other studies with PD models using 6-OHDA and MPTP also showed that treatment with melatonin, initiated shortly after administration of toxins, inhibited the onset of motor deficits. However, this effect seems to be related to the neuroprotective ability of melatonin instead of a direct action on the DAergic transmission $[135,136,138,156]$.

On the other hand, other studies failed to observe motor benefits of melatonin treatment in animal models of PD or PD patients. Medeiros et al. [206] showed that melatonin administration ( $3 \mathrm{mg}, 1 \mathrm{~h}$ before bedtime) for 4 weeks in PD patients was able to improve the quality of sleep but did not affect motor symptoms in these patients. However, the evaluation of the melatonin effect was carried out during the day without analysis of the acute effect of melatonin. Yildirim and collaborators [141] evaluated the effects of pre- 
and posttreatment with melatonin in animals that underwent a unilateral lesion with 6-OHDA in locomotor parameters, COX and caspase-3 activity, PGE2 and nitrite/nitrite levels, and apoptosis. Even though melatonin administration was able to prevent/recover parameters related to neuroinflammation and apoptosis, the pre- and the posttreatment were not able to restore the motor deficits induced by 6-OHDA injection. Moreover, Bassani et al. [161] reported that the melatonin posttreatment for 28 days preserved the $\mathrm{TH}$ positive neurons and DA levels of rotenone-lesioned rats. In addition, they also observed that melatonin improved the depressive-like behaviour, but not locomotor deficits, of these animals.

Notably, the administration of melatonin per se has been linked to a reduction in locomotor activity in naive animals. For instance, Chuang and Lin [207] demonstrated that the administration of high melatonin doses $(60 \mathrm{mg} / \mathrm{kg})$ led to a reduction in spontaneous locomotor activity of mice under normal conditions and also in response to thermal stress (cold, $4^{\circ} \mathrm{C}$, and heat, $36^{\circ} \mathrm{C}$ ). However, these changes were not observed with a lower dose of melatonin $(30 \mathrm{mg} / \mathrm{kg})$. Melatonin-treated animals showed a reduction in serotonin release in the hypothalamus, striatum, and nucleus accumbens, although DA levels were not altered. Furthermore, Willis and Armstrong [208] evaluated the effects of slow melatonin release via intracerebroventricular implants, pinealectomy, or exposure to constant light on the motor function of rats submitted to 6-OHDA or MPTP administration. Melatonin administration deteriorated motor performance, exacerbating the deficits evoked by these neurotoxins. Additionally, the experimental antagonism achieved by pinealectomy or melatonin synthesis inhibition by the exposure to light improved the induced motor deficits in PD models [208].

In this regard, previous studies have shown that light therapy may have a beneficial effect in motor and nonmotor symptoms of PD [209]. The improvement of motor symptoms by light was observed in animals with unilateral lesion with 6-OHDA, or with mechanical injury of the lateral hypothalamus [205]. Light therapy was also shown to be beneficial in PD patients. In a clinical study, 20 patients with $\mathrm{PD}$ received light therapy by exposure to fluorescent light for 1-1.5 hours at an intensity ranging between 1000 and 1500 lux, about 1 hour before bedtime. Several behavioural parameters were evaluated before the light therapy and after 2 and 5 weeks, at regular intervals.

Light therapy improved rigidity and bradykinesia, improved mood and sleep, reduced seborrhoea and impotence, and increased appetite [210]. In another study, 36 patients with $\mathrm{PD}$ received light therapy. The treatment consisted of exposure to 7500 lux illumination in the treated group and 950 lux in the placebo group, $30 \mathrm{~min} /$ day for 15 days. Patients were evaluated for motor symptoms, depression, and sleep disorders. The results revealed a significant improvement in tremors and depression presented by these patients [211]. Willis and colleagues [205] conducted a retrospective study where $129 \mathrm{PD}$ patients were monitored for periods ranging from a few months to eight years. The treatment consisted of $1 \mathrm{~h}$ of exposure to a light intensity ranging from 4000 lux to 6000 lux before bedtime. Motor and nonmotor symptoms were monitored. Patients were divided into 3 groups: patients who adhered, patients who adhered partially, and patients who did not adhere to the treatment. Patients who adhered to the treatment demonstrated an improvement of bradykinesia, rigidity, and balance. Symptoms of sleep disorders and depression also showed improvement. Additionally, increased medication was also lower in patients that fully or partially adhered in comparison to those who did not adhere.

Other studies also investigated the effects of melatonin receptors antagonism in animal models of PD. For instance, it was demonstrated that ML-23, an antagonist of melatonin receptors, enhanced the motor deficits induced by MPTP [212] and 6-OHDA [213]. This effect may be related to the interaction between the nigrostriatal and retinohypothalamic circuits, which converge towards the lateral hypothalamus. Additionally, the presence of visual impairments related to dopaminergic degeneration in patients with $\mathrm{PD}$ reinforces this concept [214].

The beneficial effects of melatonin antagonism on motor symptoms of PD can be explained by the melatonin action in the inhibition of DA release in various brain structures. This inhibition can occur at concentrations ranging from $\mathrm{nM}$ to $\mu \mathrm{M}$ and may be a consequence of the inhibition of calcium influx into neuronal terminals [215]. Studies have shown that DA metabolites exhibit a circadian variation with higher concentrations during the day and a reduction in the evening [216]. Khaldy et al. [217] demonstrated that the peak of melatonin release in $\mathrm{C} 57 \mathrm{BL} / 6$ mice coincided with a reduction of DA levels in striatum. Moreover, this circadian cycle was disrupted by pinealectomy and restored by melatonin treatment [217]. The striatal DA release also modulates the activation of NMDA receptors. It has been proposed that the inhibition of striatal DA release by melatonin could also reduce striatal neurons response to glutamate released by cortical afferents [215].

In summary, although melatonin has shown a potential in improving motor deficits in animal models of PD, these effects appear to be related to its neuroprotective capacity. Nevertheless, in animal models and PD patients with established DAergic damage, melatonin may exacerbate motor deficits [205]. Moreover, the antagonism of melatonin receptors may lead to improvement in motor symptoms [208, 213]. Further studies are necessary to better understand the balance between DA and melatonin levels in the brain as well as its role in control of motor function.

\subsection{Nonmotor Symptoms}

6.2.1. Sleep Disturbances. Sleep disorders have been increasingly associated with PD and can arise as a prodromal symptom appearing years before the motor symptoms. These disorders may also reach the patient after the PD diagnosis worsening the life quality of patients and caregivers. The appearance of these disorders may be related to the degeneration of neural structures related to the sleep control. Among the sleep disorders that precede or appear in advanced stages of PD are excessive daytime sleepiness (EDS), rapid 
eye movement (REM), sleep behaviour disorder (RBD), and insomnia [122, 218].

EDS is characterized as a chronic condition in which the individual is not able to remain awake during the day, inducing social problems and automobile accidents. Diagnosis can be performed with the use of a questionnaire such as Epworth Sleepiness Scale [218]. Studies have shown increased risk of PD in patients with EDS [87, 89]. Abbott and colleagues [219] showed an odds ratio of 3.3 for the development of PD in EDS patients monitored from 1994 to 2001. In this regard, the increase of daytime napping also has been associated with a major odds ratio of PD development in 3 different stages: established PD, recent PD, and prediagnosed PD [89]. Although there is some disagreement in the literature, the early onset of EDS has been established as a preclinical and premotor marker of $\mathrm{PD}$.

The EDS may be present in PD as a persistent state of sleepiness or "sleep attacks" in which the patient begins to sleep suddenly. Although studies about the prevalence of EDS in PD show a large variation [218], its frequency appears to increase with disease progression. Tholfsen and colleagues [220] evaluated the frequency of EDS in drugnaive PD patients and after 1,3 , and 5 years of medication. EDS frequency increased from $11.8 \%$ at the baseline to $23.4 \%$ after 5 years in these patients. This elevation can be related to progressive loss of mesolimbic DAergic neurons and other non-DAergic neuronal circuits that modulate the sleep [218]. However, DAergic drugs used in PD treatment such as LDOPA and DA receptor agonists may have sedative effects, contributing to the occurrence of EDS [221].

Changes in nocturnal sleep period may or may not be correlated with the appearance of EDS, which explains the variability in the response to the treatments that enhance nighttime sleep. Some pharmacological treatments for EDS have been tested such as modafinil, caffeine, and amphetamine [221]. Modafinil is the most studied drug for this use; however, it shows modest effects on subjective parameters. Its mechanism of action is not completely understood but evidences suggest a link with the modulation of hypothalamic sleep-wake system. Modafinil promotes an increase in wakefulness by stimulating the tuberomammillary nucleus activity and reducing the promotion of sleep exerted by the ventrolateral preoptic area [221]. Caffeine did not provide benefits to sleepiness, but the patients displayed an improvement in motor symptoms of PD. Methylphenidate is an amphetamine that has shown some effect in reducing fatigue in PD patients; however, this drug has a high potential for the development of abuse [221].

The light treatment has been associated with improvement of the EDS symptoms. Mishima et al. [222] demonstrated that EDS was associated with the appearance of changes in melatonin levels and that the application of bright light therapy produced significant enhancements in symptoms. However, no study has evaluated the effect of light therapy in EDS presented in PD patients.

The relation between melatonin levels and EDS onset in patients with PD is still poorly explored. The cross-sectional study conducted by Videnovic and colleagues [87] with PD patients regularly receiving DAergic therapy revealed a diminished melatonin release. In addition, PD patients with EDS exhibited a lower release of melatonin than PD patients without EDS. Nevertheless, exogenous melatonin was not effective on EDS [223].

RBD is a parasomnia whose main features are the nocturnal dream enactment behaviour and loss of atonia of skeletal muscles. Abnormal motor behaviour (kicking) and vocals (screaming, laughing, and crying) also are commonly found in patients with this disorder. The motor symptoms provide fracture risk for the patient and their bed partner. The magnocellular nucleus in the medulla and subcoeruleus locus, which are related to the control of atony, appears to be altered in RBD. The appearance of RBD has been strongly linked to an increased risk of PD [121, 218, 224]. Schenck et al. [225] found that $38 \%$ of RBD patients evaluated in their study also have PD. In agreement, Iranzo and colleagues [226] observed that, of 44 patients diagnosed with idiopathic RBD (IRBD), 81\% (36 patients) presented some degenerative syndrome, among them 16 have PD. The survival rate without any neurodegenerative syndrome from diagnosed IRBD patients was $65.2 \%$ at 5 years, $26.6 \%$ in 10 years, and $7.5 \%$ in 14 years. Thus, the diagnose of IRBD appears as a promising tool to assist in early diagnosis of PD.

Besides being present in the premotor phase of PD, RBD also follows the progression of motor symptoms of this disease. A study evaluating 57 patients newly diagnosed with PD and still without the use of DAergic therapy showed that $30 \%$ (17 patients) of the individuals had symptoms of RBD [227]. Other studies that investigated the presence of RBD in PD patients treated with DAergic drugs have found prevalence values ranging between $46 \%$ and $58 \%$ [228, 229]. Gjerstad and colleagues [230] evaluated the presence or absence of RBD in 231 patients with $\mathrm{PD}$ reexamining them after 4 and 8 years. Their data exhibited an elevation in the RBD frequency in these patients, from $14.6 \%$ to $27 \%$, during the study period. This increase was associated with higher doses of L-DOPA and less Parkinsonism, firming the role of DAergic therapy in the onset of sleep-related disorders.

Although other studies have evaluated melatonin effect in improving sleep quality using subjective scales, only one study investigated the effect in patients diagnosed with RBD [206, 231]. Kunz and Bes studied six patients diagnosed with RBD who received treatment for 6 weeks with $3 \mathrm{mg}$ of melatonin daily, 30 minutes before bedtime. As a result, a dramatic improvement in the symptoms of RBD in 5 patients within a week was observed and this improvement remained after discontinuation of treatment for weeks or months. Polysomnography performed 6 months later revealed that several parameters of REM sleep were normalized.

Insomnia is one of the most common sleep disorders in PD patients and its emergence may be related to uncontrolled motor symptoms, nocturia, depression, and circadian cycle disruption [218]. In a recent study, 689 patients with PD were submitted to a questionnaire in order to evaluate the quality of sleep. This study showed that the total number of patients who presented chronic inability to sleep was $36.9 \%$; $18 \%$ had difficulty in initiating sleep, $81.54 \%$ interrupted sleep, $40.4 \%$ early morning awakenings, and $38.5 \%$ nonrestorative sleep [232]. 
Given the importance of the overnight motor symptoms in PD in the emergence of insomnia, treatments with DAergic drugs in order to reduce the night Parkinsonism have exhibited good efficacy. In this regard, studies assessing the benefits of slow release formulations of ropinirole, rotigotine, or L-DOPA showed an improvement in the sleep quality of patients with PD [233-235]. Several drugs are currently approved for the treatment of insomnia; however, only eszopiclone, an agonist of $\mathrm{GABA}_{\mathrm{A}}$ receptors, and doxepin, a tricyclic antidepressant, showed some efficacy in the treatment of insomnia in PD patients [221].

The role of melatonin in PD patients who suffer from insomnia is controversial. Although some studies have shown that treatment with different doses of melatonin leads to an improvement in the sleep quality, assessed subjectively by questionnaires or through polysomnography tests [206, 231], other studies show that the light therapy was beneficial for these patients [236]. PD patients exposed to a light intensity of 10000 lux ( $90 \mathrm{~min} / 6$ times a week) obtained an improvement in the insomnia, but there was a worsening in the questionnaires related to the symptoms of PD [237]. Other sleep disorders such as obstructive sleep apnoea, restless legs syndrome, and periodic leg movements during sleep are also often present in PD patients [218], but there is no specific study that associates these disorders with the modulation of the melatoninergic system.

As noted, even though progress has been made towards the characterization of sleep disorders during PD progression and the possible relationship with the melatoninergic system, more studies are needed for the development of effective therapeutic approaches that improve the quality of life of patients and caregivers.

6.2.2. Cognitive Deficits. Prevalence of cognitive deficits in PD patients has been poorly investigated [238]. A study carried out in the UK revealed that $36 \%$ of $\mathrm{PD}$ patients had cognitive impairment at least in one of three cognitive tasks performed: Minimental State Examination, a pattern recognition task, and the tower of London task [239]. Another report comparing untreated PD with controls found twofold increase in the proportion of cognitive dysfunction. Nevertheless, the lack of criteria for diagnosing cognitive impairment in PD patients makes these studies difficult to reproduce and compare [238].

Cognitive deficits detected in PD differ from individual cognitive impairment to minimal cognitive dysfunction to full-blown dementia like, being divided into mild cognitive impairment (MCI) or severe, leading to the dementia diagnosis (PD dementia (PDD)). This nonmotor symptom of PD may result from the natural course of the disease or could be associated with treatment interventions, such as adverse effects of drugs and deep brain stimulation (DBS). Executive function, memory, and visuospatial deficits are the three cognitive impairments more commonly detected in PD [238].

Executive function comprises essential abilities related to the decision-making process, such as retrieval from declarative memory, management of information in working memory, and cognitive flexibility and planning. Some studies have observed that executive dysfunction is higher during early phase of PD and also that this impairment is a predisposing factor for greater severity of PD [240]. Also, memory deficits, working memory, short-term memory, visual shortterm memory, declarative memory, and recognition memory are impaired in PD patients [238]. However, long-term and verbal short-term memory are not altered and explicit memory was shown to be partially lost [238].

Visuospatial dysfunction is well known in PD. Montse et al. [241] demonstrated that a decrease in spatial orientation functioning in $\mathrm{PD}$ may elicit the progression rating of the disease as reflected by three determinants variables found: age, duration of disease, and degree of dementia. Moreover, motor involvement has been suggested as major criterion for reduction of this memory, even in the early stages of the illness.

The pattern of cognitive deficits assessed in patients by cognitive tasks suggests the existence of subgroups, which may reflect regional differences in the underlying neuropathological processes [239]. In this way, grey matter loss in most of the brain regions has been correlated with a decrease of global cognitive score, but not with motor impairment. MCI subjects showed partial atrophy of grey matter in the temporal, parietal, and frontal cortex, bilateral caudal hippocampus, amygdala, and right putamen. Brain atrophy occurs as a consequence of the cell death, which is largely attributed to the formation of Lewy bodies in PDD [242].

There is increasing evidence about the role of melatonin in learning and memory processes (Table 3). Wang et al. [169] revealed a concentration-dependent inhibition of longterm potentiation (LTP) by melatonin in the CA1 dendritic layer of the Schaffer collateral of hippocampal slices in mice. LTP is a process in which the neuronal association is cooperatively and selectively strengthened by elevated synaptic activity through glutamate NMDA and $\alpha$-amino-3hydroxy-5-methyl-4-isoxazolepropionic acid (AMPA) receptors. Melatonin acts on LTP by modulating the postsynaptic nitric oxide (NO) signalling pathway [243]. Thus, this link between melatonin and LTP implies its role in the memory formation [169]. In addition, plasma melatonin levels decrease during aging, being related to the decline of neurogenesis and probably to cognitive alterations [244]. Despite this, the effect of melatonin on cognitive dysfunctions in PD has been poorly investigated, whereas more attention has been given to cognitive impairment in $\mathrm{AD}$.

Datieva et al. [245] evaluated the effect of melatonin in 30 patients with early and late stages of PD and no significant difference was observed in cognitive autonomic disorders when compared to baseline. Using a MPTP rat model of PD, Capitelli et al. [246] investigated the effects of melatonin pretreatment $(50 \mathrm{mg} / \mathrm{kg}$, i.p.) in the animals' performance of two-way active avoidance task. The memory acquisition and retention process were impaired by MPTP, and melatonin was unable to restore this deficit.

The association between melatonin and cognitive dysfunction in PD was further addressed in animal models of PD using the novel object recognition (NOR) [247, 248], Morris water-maze (MWM), and passive avoidance tasks [249]. Agomelatine, an agonist of melatoninergic $\mathrm{MT}_{1}$ and $\mathrm{MT}_{2}$ 
TABLE 3: Summary of studies investigating the role of melatonin and its receptors in LTP and learning and memory processes.

\begin{tabular}{|c|c|c|c|c|}
\hline Experimental approach & LTP & Main findings & MT receptor involved & Ref. \\
\hline Melatonin $1 \mathrm{nM}$ & Inhibits & Melatonin inhibits $\mathrm{GABA}_{\mathrm{A}}$ via $\mathrm{MT}_{2}$. & $\mathrm{MT}_{2}$ & {$[166]$} \\
\hline Melatonin 0.1 to $2.0 \mathrm{mM}$ & Inhibits & $\begin{array}{l}\text { Luzindole, an antagonist of MT receptors, } \\
\text { blocks the inhibitory effect. }\end{array}$ & MT & {$[167]$} \\
\hline Melatonin $100 \mu \mathrm{M}$ & Inhibits & $\begin{array}{l}\text { BMNEP, a specific ligand of the } \mathrm{MT}_{2} \\
\text { receptors, mimics the inhibitory action. }\end{array}$ & $\mathrm{MT}_{2}$ & {$[168]$} \\
\hline $\begin{array}{l}\text { Melatonin } 0.1 \mathrm{nM} \text { to } \\
100 \mu \mathrm{M} \text {; } \\
\mathrm{MT}_{1}^{-/-} \text {mice and } \mathrm{MT}_{2}^{-/-} \\
\text {mice }\end{array}$ & Inhibits & $\begin{array}{l}\text { Melatonin inhibitory action is prevented } \\
\text { by luzindole and } \\
\text { 2-propionamidotetraline, an } \mathrm{MT}_{2} \\
\text { antagonist. } \\
\mathrm{MT}_{2}^{-/-} \text {mice lost inhibitory effect on LTP, } \\
\text { but not } \mathrm{MT}_{1}^{-/-} \text {mice. }\end{array}$ & $\mathrm{MT}_{2}$ & [169] \\
\hline $\mathrm{MT}_{2}^{-/-}$mice & Inhibits & $\begin{array}{l}\text { Slices from } \mathrm{MT}_{2}^{-/-} \text {mice exhibited } \\
\text { smaller and decrement LTP compared to } \\
\text { wild type mice. } \\
\mathrm{MT}_{2}^{-l-} \text { mice showed impairment in the } \\
\mathrm{EPM}^{-l} 2 \text { consecutive days. }\end{array}$ & $\mathrm{MT}_{2}$ & {$[170]$} \\
\hline $\mathrm{MT}_{1} / \mathrm{MT}_{2}{ }^{-/-}$mice & Enhances & $\begin{array}{l}\mathrm{MT}_{1} / \mathrm{MT}_{2}{ }^{-/-} \text {mice demonstrated } \\
\text { improvement in cognitive performance in } \\
\text { the Barnes- and Y-maze tests. }\end{array}$ & $\mathrm{MT}_{1} / \mathrm{MT}_{2}$ & {$[171]$} \\
\hline
\end{tabular}

receptors and an antagonist of serotonergic $5-\mathrm{HT}_{2 \mathrm{C}}$ receptors, also elicits positive effects on memory [247]. Its chronobiotic activity on cognitive functions was investigated in the $\mathrm{T}$ maze left-right spatial discrimination test showing a more intense effect when administered in the evening and in the NOR exhibiting improvement in the memory independent of the administration period. Involvement of melatoninergic agonist and $5-\mathrm{HT}_{2 \mathrm{C}}$ antagonist properties could be related to the memory facilitating effect of agomelatine [247]. Neu-P11, a melatoninergic $\left(\mathrm{MT}_{1} / \mathrm{MT}_{2}\right)$ receptors agonist and serotonin $5-\mathrm{HT}_{1 \mathrm{~A} / \mathrm{ID}}$ agonist, was able to enhance the memory in the NOR and against deficit induced by $\mathrm{A} \beta_{(1-42)}$ peptide [248].

Considering that sleep problems have been shown to contribute to neuropsychological deficits in otherwise healthy people, the nootropic effect of melatonin has been associated with its positive effect on sleep quality. As mentioned before, there is a high prevalence of sleep disturbances in PD patients, which are improved with melatonin treatment. Meta-analysis demonstrated a significant effect of sleep on global cognitive function, long-term verbal recall, long-term verbal recognition, shifting, updating, and fluid reasoning. Specifically in $\mathrm{PD}$, an association between sleep disorders and memory and executive function deficits was found. However, this outcome should be analysed carefully due to the small number of studies and numerous methodological issues identified in them [250].

Furthermore, the differential role of MT receptors has also been investigated, mainly in the hippocampus, in order to elucidate nootropic effect of modulators in this system (Table 3). $\mathrm{MT}_{1} / \mathrm{MT}_{2}$ double knockout mice displayed ameliorated spatial and reference learning and memory performance in the Barnes maze and the Y-maze tests. These behavioural findings were consistent with the enhancement of LTP and brain p-CREB, p-ERK1/2, and key markers of synaptic activity expression levels [171]. However, other studies observed hippocampus LTP inhibition by melatonin that was blocked by MT receptors antagonist [167] and by selective $\mathrm{MT}_{2}$ receptor antagonist, suggesting a mediated effect by $\mathrm{MT}_{2}$ receptor [168]. This hypothesis was confirmed using $\mathrm{MT}_{1}$ knockout and $\mathrm{MT}_{2}$ knockout mice, in which the inhibitory LTP action of melatonin was lost in $\mathrm{MT}_{2}{ }^{-/-}$mice, but not in $\mathrm{MT}_{1}^{-/-}$mice [169].

This prevalent involvement of $\mathrm{MT}_{2}$ receptor in the memory and cognitive functions has been demonstrated in the literature. Larson et al. [170] corroborate the data of Wang et al. [169], demonstrating smaller and decrement LTP in hippocampus slices from $\mathrm{MT}_{2}{ }^{-/-}$mice. In addition, $\mathrm{MT}_{2}{ }^{-/-}$ mice showed learning deficits in the elevated plus-maze test (EPM) in two consecutive days, failing to shorten the transfer latencies to enter a closed arm on the second day. Comai and Gobbi [251] also report that $\mathrm{MT}_{2}{ }^{-/-}$mice spent more time in the central platform of EPM, which could be linked to an impaired decision taking and cognitive flexibility.

Thus, these studies suggest an important role for melatoninergic system in memory and cognition function, probably linked to underlying process of LTP by $\mathrm{MT}_{2}$ receptor. Nevertheless, due to contrasting results, more studies are required to clarify the role of melatoninergic modulators in LTP, as well as the importance of each MT receptor in this regard. After this, the potential use of melatoninergic modulators as cognitive enhancers, mainly for cognitive impairment linked to sleep disorders in $\mathrm{PD}$ and $\mathrm{AD}$, should be considered in clinical and preclinical tests.

6.2.3. Depression. Depression represents one of the most common nonmotor symptoms in PD, occurring in 50$70 \%$ of patients $[252,253]$. Many other diseases that affect elderly people also have depression as common symptom. However, patients with PD are more susceptible to developing depression than the general elderly population or patients with other chronic and disabling diseases [252]. In a recent 
study conducted with more than 1400 individuals, depression was found to be more common in female than in male patients and had a bigger prevalence in individuals in the advanced stages of PD or in individuals that developed dementia [254].

Depression is an important feature to determine the quality of life in PD patients, and the caregivers of individuals with PD are also affected by the course of the disease [253]. Therefore, understanding depression in PD is a crescent need among all the professionals involved with this disease.

The aetiology of depression in PD is unclear, but alterations in neurotransmitters (monoaminergic) systems and limbic Lewy body pathology might contribute to this disorder. Besides, other previous pathologies like cerebrovascular disease and neurotrophic changes are also related to depression in PD. There is a hypothesis that claims that the monoaminergic deficits and lesions of frontal-subcortical circuits are the same in the brain of patients with PD and those with depression [118].

The main symptoms of depression are depressed mood, loss of pleasure (anhedonia), and feelings of worthlessness and guilty. The depressive syndrome also includes some somatic symptoms such as loss of appetite, sleep disturbances, psychomotor retardation, and altered facial expression [252]. However, these symptoms could also be present in PD patients without the depressive symptoms and the differentiation between these two situations is a great challenge for clinicians.

There are few studies investigating the course of depression among different stages of PD. One of the most important studies in the field evaluated patients with PD who were also diagnosed with major depression. One year later, the majority of these patients still showed major depression and the risk of dementia or a fast cognitive decline that was associated with major depression [255]. Nevertheless, more long-term studies that associate depression and PD are needed to clarify the predictors and prognostic of these patients.

There are contradictories views about depression as a nonmotor symptom of PD or a risk factor for PD development. Jacob et al. [256] and collaborators findings support the hypothesis that depression is a prodromal symptom of PD and not a risk factor for the disease. In a two-year study, it was observed that the development of PD was more common in individuals who had used antidepressants than among nonusers [257].

Depression and PD share some abnormalities in brain structure. In the SNc, there is a hyperechogenicity and in the brainstem raphe there is a reduced echogenicity. These alterations are common and severe in patients who have both PD and depression, and these changes are usually related to a history of depression before the development of PD [258]. Patients with PD and depression also presented a profound loss of striatal DAT availability and frontal hypoperfusion compared with nondepressed patients [252, 253]. These observations, besides confirming that depression can precede $\mathrm{PD}$, are in agreement with Braak hypothesis of $\mathrm{PD}$, in which the neurodegeneration in regions like the noradrenergic coeruleus-subcoeruleus complex and the serotonergic caudal raphe nucleus occurs before the motor symptoms [259].
Defining the mechanism behind depression in PD is very difficult. When people older than 65 years are affected by depression, there are numerous variables involved such as psychosocial issues, genetic factors, and age-related brain alterations that should be considered. In patients with PD that also develop depression, it is necessary to consider the involvement of factors like monoaminergic disturbances, cerebrovascular diseases, Lewy body pathology, functional changes in the limbic and subcortical circuits, hippocampal atrophy, alterations in neurogenesis and neurotrophic factors, and toxic stress, besides hypercortisolemia and inflammation [252].

The neurotransmitter systems affected in patients with depression and PD involve the noradrenergic, DAergic, and serotonergic pathways. These systems are also related to regulation of mood, and deregulations of these are associated with depression in the general population. Patients with PD and depression were shown to have increased serotonergic neuronal cell loss in the dorsal raphe nucleus and decreased levels of striatal serotonin and its transporter. The disruption of the nigrostriatal DA as well as other DAergic pathways in limbic and frontal circuits, and the loss of DAergic neurons in the ventral tegmental area, are also related to depression in PD. Indeed, the locus coeruleus is affected in early stages of PD and the increase of neurodegeneration in this area is correlated with depressed individuals with PD. Cognitive and mood impairments associated with PD could also be related to cholinergic deficits. Furthermore, new evidence suggests that stress hormones, immunomodulatory mediators, neurotrophic factors, and neuropeptides are also involved in the aetiology of depression in PD [252].

Although depression is highly prevalent among individuals with PD, a proper therapy for this disorder has not been well defined. The options of treatment for depression in PD found in literature are limited by a small sample size, short duration of action, design issues, or incompatible outcome measurements [253]. The classic options for the treatment of depression in PD include selective serotonin reuptake inhibitors (SSRI) (citalopram, sertraline, fluoxetine, and paroxetine); serotonin-noradrenalin reuptake inhibitors (SNRI) (desipramine, amitriptyline, nortriptyline, and doxepin); and some atypical agents as trazodone and nefazodone. These are also examples of the main medications used to treat depression in general population. Pramipexole, pergolide, atomoxetine, and memantine are also used, even though they are not so common. Finally, bupropion, a noradrenaline and DA reuptake inhibitor, is normally used to treat depression in PD patients and has effects under the depressive and motor symptoms $[123,124]$.

Depression in PD has a heterogeneous aetiology and responsiveness to treatments, and although there are a wide variety of treatment options, not all the patients with depression and PD respond to these drugs. Therefore, new strategies and new targets have been investigated to improve the current therapy and assure a good prospect of quality of life for these patients [124]. Melatonin is one of the substances that show beneficial effects for depression in PD patients.

The potential therapeutic effect of melatonin in mood disorders has been studied recently, because many patients 
with depression presented disruption in melatonin circadian profile $[161,260]$. Preclinical studies demonstrated that melatonin has antidepressant-like effects in several animal models of depression, such as in the forced swimming test [260], tail suspension test [261, 262], chronic mild stress paradigm [263], and nonmotor symptoms of a rodent model of PD [161].

In order to document the association between sleep and mood disorders, different studies in humans have been done demonstrating that the treatment with melatonin improves the total sleep time and decreases depressive symptoms. A new pharmaceutical tool for treating and preventing depression contains an association between a SSRI and melatonin; this association had a markedly positive impact on the sleep-wake rhythm of depressive patients [264]. Circadian disruption is linked to the changes in behaviour and sleep patterns that occur in depression, and this disease is associated with alterations in diurnal rhythm of melatonin output [265].

In the rotenone model of $\mathrm{PD}$, the prolonged treatment with melatonin prevented the appearance of depressivelike behaviour, and this melatonin antidepressant effect was associated with its ability to restore the striatal DA levels [161]. Another study demonstrated that the antidepressantlike effect of melatonin in the tail suspension test could be associated with its direct interaction with $\mathrm{DA}_{1}$ and $\mathrm{D}_{2}$ receptors [262]. Furthermore, the antidepressant effect of melatonin may also be attributed to the protection against the loss of DAergic neurons and the modulation of DAergic neurotransmission [161].

Since alterations in circadian rhythms are also implicated in the aetiology of depression and PD, dysfunction in the rhythmicity of circadian cycle is very common among PD patients with depression $[161,265]$. Another important fact to be observed about melatonin and depression in PD is that the DAergic neurons in the nigrostriatal pathway are melanocytes, and the melatonin and DA coexist in a functional opposition regulating day/night activities. Thus, it is likely that the exogenous melatonin administration may alter the balance between DA and melatonin. In the study of Bolitho et al. [266], the DAergic treatment for PD profoundly increased the secretion of melatonin, regulating the circadian cycle and sleep timing.

Considering the relevance of circadian cycle in the pathogenesis of depression and PD, a new approach has been proposed for the treatment of this disorder using the melatonin analogous agomelatine. This drug is associated with the resynchronization of circadian rhythms and was shown to have antidepressant effect in humans.

Overall, from these limited results in this field, it appears that melatonin and melatonin analogous might be particularly useful to improve the depression in $\mathrm{PD}$, but further studies are needed for the development of effective therapeutic approaches that improve the quality of life of patients and caregivers.

6.2.4. Anxiety. Despite the high prevalence of anxiety in PD patients, this issue has only recently attracted scientific attention. Anxiety disorder presents itself as the second mood disturbance most common in $\mathrm{PD}$, with major impact on daily functioning and quality of life in patients [267].

Prevalence of anxiety in PD patients depends on the study sample features and methodology used to assess this nonmotor symptom [268]. Many studies suggest that approximately $20-50 \%$ of PD patients experience clinically relevant symptoms of anxiety $[269,270]$. Generalized anxiety disorder (GAD), social phobias, panic attacks, and anxiety disorder Not Otherwise Specified (NOS) are the anxiety syndromes more often reported in PD when using the Diagnostic and Statistical Manual (DSM) of mental disorders criteria for the assessment [271]. Nevertheless, DSM has questionable validity to assess anxiety in $\mathrm{PD}$, since symptoms in $\mathrm{PD}$ patients are atypical and therefore are classified as NOS [272]. Recently, Dissanayaka et al. [273] recommended the use of Parkinson's Anxiety Scale (PAS) and Geriatric Anxiety Inventory (GAI) in PD without dementia in order to present satisfactory psychometric features.

Anxiety is a nonmotor symptom of PD that can precede the onset of motor symptoms or develop after the diagnosis of the disease [268]. In order to understand the risk factors linked to anxiety in PD, Broen et al. [274] delineated a model using PD-specific and nonspecific factors. Previous history and the severity of depressive symptoms were considered nonspecific risk factors, which showed direct effect on anxiety. On the other hand, motor fluctuations and diseaserelated decline in daily activities were considered PD-specific factors and display less influence in the model.

Rutten et al. [275] concluded in their study that anxiety in $\mathrm{PD}$ involves affective and somatic symptom dimensions. In fact, several authors have associated anxiety disorders with severe gait problems [270], dyskinesias/fluctuations [270, 271], freezing [276], and depression [267, 270, 274, 276]. Furthermore, depression, urinary disorders, and sleep disruption were found as factors most likely to influence anxiety in PD [272].

Neurobiological alterations related to anxiety in PD are based on two theories $[268,269]$. The reactive theory is associated with the diagnostic of PD and therefore with the DAergic lesion and motor impairment [271, 276]. DAergic involvement is supported by positive relationship between anxiety and motor fluctuations and withdrawal of DAergic medication or DBS [111]. Additionally, the mesolimbic DAergic pathway, in which neurodegeneration is observed in $\mathrm{PD}$, sends projections to the amygdala, a key brain structure for the production and regulation of anxiety [277].

In contrast, psychological symptoms could result from early neurochemical changes; hence, epidemiologic observations demonstrate that PD patients have greater predisposition to anxiety disorders before the diagnosis [256]. Thus, anxiety may be a premotor symptom of PD linked with other neurotransmitters systems such as noradrenergic and serotonergic systems [269, 278]. Braak staging scheme for PD suggests early neurodegeneration of the raphe nucleus and the locus coeruleus, structures with abundance in serotonin and noradrenaline, respectively. Serotonin depletion results in an increased anxiety in PD [223], whereas noradrenaline reduction leads to a high frequency of anxiety in PD [279]. Additionally, other neurotransmitter systems 
TABLE 4: Animal studies addressing the effects of melatonin on anxiety-like responses.

\begin{tabular}{|c|c|c|c|c|}
\hline Test & Gender, species, stain & Melatonin treatment & Effects & Ref. \\
\hline OFT & Male, rat, Wistar & $1 \mathrm{mg} / \mathrm{kg}$, i.p. & Anxiolytic & {$[172]$} \\
\hline EPM & Male, rat, Wistar & $\begin{array}{l}1-20 \mathrm{mg} / \mathrm{kg}, \text { i.p. at } \\
12: 00 \mathrm{~h} \text { or } 18: 00 \mathrm{~h}\end{array}$ & Anxiolytic during the dark phase & {$[173]$} \\
\hline FET, LDT & Male, mouse & $0.5-5 \mathrm{mg} / \mathrm{kg}$, i.p. & Anxiolytic & {$[174]$} \\
\hline Vogel test & Male, rat, Wistar & $0.1-2.0 \mathrm{mg} / \mathrm{kg}$, i.p. & Anxiolytic & [175] \\
\hline FET, LDT & Male, mouse, $\mathrm{C} 3 \mathrm{H} / \mathrm{He}$ & 5-25 mg/kg, p.o. & Anxiolytic & [176] \\
\hline $\begin{array}{l}\text { EPM, Vogel test, USV, } \\
\text { social interaction test (SIT) }\end{array}$ & Male, rat, Wistar & $2.5-80 \mathrm{mg} / \mathrm{kg}$, i.p. & $\begin{array}{l}\text { Anxiogenic at } 80 \mathrm{mg} / \mathrm{kg} \text { on the SIT } \\
\text { No effect on the other tests }\end{array}$ & {$[177]$} \\
\hline EPM, Vogel test, USV & Male, rat & $\begin{array}{l}10-75 \mathrm{mg} / \mathrm{kg} 2 \mathrm{~h} \text { before } \\
2 \mathrm{~h} \text { after the dark phase }\end{array}$ & $\begin{array}{l}\text { Anxiolytic on the EPM } 2 \mathrm{~h} \text { after the } \\
\text { dark phase } \\
\text { No effect on the Vogel test and USV }\end{array}$ & [178] \\
\hline Vogel test & Male, rat, Wistar AF & $\begin{array}{l}20-80 \mathrm{mg} / \mathrm{kg}, \text { i.p. at } \\
17: 00 \text { to } 20: 00 \mathrm{~h}\end{array}$ & Anxiolytic & [179] \\
\hline EPM & Male, rat, Sprague-Dawley & $\begin{array}{l}50 \mathrm{mg} / \mathrm{kg} \text {, i.p. in the } \\
\text { morning and afternoon }\end{array}$ & Anxiolytic in the afternoon & [180] \\
\hline EPM, OFT & Male and female, rat, Wistar & $\begin{array}{l}4 \mathrm{mg} / \mathrm{kg} \text {, s.c. at } 16: 00 \mathrm{~h} \\
\text { for } 8 \text { weeks }\end{array}$ & $\begin{array}{c}\text { Anxiolytic } \\
\text { Gender-dependent }\end{array}$ & {$[181]$} \\
\hline EPM, OFT, NSF & Male, rats, Sprague-Dawley & $20 \mathrm{mg} / \mathrm{kg}$, s.c. & $\begin{array}{l}\text { Anxiolytic on the EPM and NSF } \\
\text { No effect on the OFT }\end{array}$ & {$[182]$} \\
\hline
\end{tabular}

EPM: elevated plus-maze test; FET: free exploratory test; LDT: light/dark box test; NSF: novelty-suppressed feeding test; OFT: open field test; USV: ultrasonic vocalization.

such as gamma-aminobutyric acid (GABA) and glutamate neurotransmitters were shown to be altered in PD patients and may also influence anxiety [268, 269].

In spite of the data mentioned, the anxiety in $\mathrm{PD}$ is underdiagnosed and undertreated. The treatment of anxiety in patients with PD is the same as that in patients without PD, which is similar to depression treatments [269]. Even though depression and anxiety are frequently comorbid [270, 280], they are distinguished from each other, exhibiting distinct trajectories and different longitudinal relationships with demographic, motor, and nonmotor factors that were unique to each disorder [280].

The benzodiazepine (BDZ) midazolam was compared to melatonin on the perioperative effects in a double-blinded, placebo-controlled study [281]. Both treatments were able to decrease anxiety levels and elevate levels of sedation when compared to control subjects. Nevertheless, midazolam, tested at three different doses, induced impairment in the psychomotor skills and performance on the digit-symbol substitution test at all evaluated time points. Melatonin, at a dose of $0.05 \mathrm{mg} / \mathrm{kg}$, was associated with preoperative anxiolysis and sedation without cognitive and psychomotor deficits. Preclinical trials also were carried out with melatonin and BDZ. Guardiola-Lemaître et al. [236] observed that melatonin enhanced anxiolytic-like action of diazepam in mice submitted to the four plates and tail suspension tests.

Anxiolytic effect of melatonin has also been evaluated on several behavioural tests of anxiety (Table 4). The first evidence of its influence on anxiety was obtained in rats by Golus and King [172] in the open field (OF) test. After this, anxiolytic-like activity of melatonin has been observed in several behavioural animal tests, such as light/dark box (LD), elevated plus-maze (EPM), and Vogel tests [173-176, 178182]. Papp et al. [178] reported the capacity of melatonin in increasing the open-arm exploration at the EPM only in the evening experiment and proving itself inactive in the Vogel and ultrasonic vocalization tests independent of timing [178]. Nonetheless, Millan et al. [177] data do not corroborate this conclusion. The variability found in the results may be related to dose and time of delivery, but there is a consensus that anxiolytic melatonin's effect is strongly time dependent $[173,179,180]$ (Table 4).

In relation to clinic findings, Datieva et al. [245] described the effectiveness of melatonin in decreasing the anxiety state on Spielberger's scale without altering motor, cognitive autonomic, and depression levels in patients with early and late stages of PD. Melatonin treatment also presented itself as useful as an anxiolytic in perioperative treatment in nine of the ten studies. In addition, plasma melatonin is diminished at night in patients with panic disorder, which has an increased prevalence in PD patients [282].

Other modulators of melatoninergic system have been investigated on anxiety disorders. Agomelatine, Neu-P11, and UCM765 presented anxiolytic effects in behavioural animal tests independent of the timing of administration $[177,178,180,182]$, without inducing sedation [178]. Clinical data suggest that agomelatine has anxiolytic potential, which proved to be equal or higher than SSRIs and SNRIs for the treatment of GAD, a common anxiety disorder in PD [283]. Case reports suggest a potential of agomelatine as treatment for social anxiety [284] and panic disorders [285]. Kalyn et al. [286] assessed therapeutic efficacy, tolerability, and safety of agomelatine in elderly patients observing positive results in depression, anxiety, and anhedonia indicators. On the other 
hand, anxiolytic action of UCM765 was shown to be mediated by $\mathrm{MT}_{2}$ receptors [182] and anxiety levels did not alter in $\mathrm{MT}_{2}{ }^{-/-}$mice in the EPM [251].

Different effects on anxiety found among melatonin and melatoninergic agonists mentioned here suggest the involvement of other neurotransmitter systems. The use of S22153, a melatonin receptor antagonist, was shown to block both melatonin and agomelatine anxiolytic effects in the EPM at night [178], reinforcing the participation of MT receptors in the nocturnal action. However, Millan et al. [177] did not report the same effect, suggesting that the anxiolytic action of agomelatine is more related to $5-\mathrm{HT}_{2 \mathrm{C}}$ antagonism. Recently, the capacity of $\mathrm{MT}_{2}$ and $5-\mathrm{HT}_{2 \mathrm{C}}$ receptors to assemble into functional heteromers was identified, indicating a potential involvement of these heteromers in agomelatine effect [51]. The maintenance of anxiolytic action of agomelatine in daytime also corroborates the modulation of serotoninergic system. In addition, there are several evidences of the contribution of the GABAergic system to melatonin, agomelatine, and Neu-P11 effects [173, 174, 179, 180].

Melatonin can bind to GABA receptors like BDZ, barbiturates, and GABA, enhancing chloride influx [287]. Furthermore, enhancement or attenuation of $\mathrm{GABA}_{\mathrm{A}}$ receptormediated currents strongly depends on melatonin receptors activation [287]. Indeed, melatonin potentiated GABAevoked current amplitude in suprachiasmatic nucleus, which express $\mathrm{MT}_{1}$ receptors, and decreased in hippocampal CA1 neurons, which express $\mathrm{MT}_{2}$ receptors [166]. Pharmacological interventions also elicit the involvement of GABAergic system in the effect of melatonin [173, 174, 236]; and in humans it has been used to reduce or eliminate BDZ administration in elderly patients [251].

Therefore, there are many studies supporting the anxiolytic potential of melatonin and other melatonin receptors agonists, demonstrating the cross talk between melatoninergic, GABAergic, and serotoninergic systems. Nonetheless, its use in $\mathrm{PD}$, a disease with high prevalence of anxiety disturbances, has been underinvestigated in both preclinical and clinical studies.

Although research is at an early stage, the findings reviewed above highlight the sleep, memory, and anxietyand mood-enhancing properties of melatonin in humans and rodents. Therefore, the performance of additional preclinical and clinical studies to verify the effects of melatonin and new drugs acting on melatoninergic system in the nonmotor symptoms of PD appears to be a promising field.

\section{Conclusions}

This article reviews the recent evidence that the melatonin plays an important role not only as a modulator of lightdark cycle, but fundamentally as an important factor for neuronal plasticity, protection, and survival in the CNS. Possible therapeutic opportunities for neurological disorders through the modulation of melatoninergic system are presented in the expectancy that this review may inspire clinical researchers and foster experimental approaches using melatonin receptors $\mathrm{MT}_{1}$ and $\mathrm{MT}_{2}$ as therapeutic targets.
Melatonin has anti-inflammatory and antioxidant properties acting as a free-radical scavenger, reducing hydroxyl free radicals, and improving mitochondrial homeostasis. It also regulates the expression of neurotrophins that are directly involved in the survival of dopaminergic neurons and reduces the aggregation of $\alpha$-synuclein restoring deficits in the DAergic system. The unbalance of pineal melatonin synthesis can predispose the organism to inflammatory and neurodegenerative diseases such as PD. The literature reviewed here indicated that $\mathrm{PD}$ is associated with impaired brain expression of melatonin and its receptors $\mathrm{MT}_{1}$ and $\mathrm{MT}_{2}$. Moreover, melatonin administration has demonstrated an outstanding neuroprotective effect in animal models of PD induced by different toxins such as 6-OHDA, MPTP, rotenone, paraquat, and maneb. These studies have shown promising results with the improvement of motor deficits in animal models of PD and notably in nonmotor symptoms such as sleep disorders, anxiety, depression, memory, and cognition dysfunctions that are part of the symptoms commonly experienced by PD patients.

Future research aiming at the development of novel melatonin receptor selective ligands will help to elucidate the neurobiology and physiological role of melatonin as well as its potential as a novel palliative and neuroprotective agent in PD.

\section{Competing Interests}

The authors have no financial or personal conflict of interests related to this work.

\section{Acknowledgments}

Some of the research reviewed in this article was supported by the Brazilian agencies Conselho Nacional de Desenvolvimento Científico e Tecnológico (CNPq), Coordenação de Aperfeiçoamento de Pessoal de Nível Superior (CAPES), Programa de Apoio aos Núcleos de Excelência (PRONEX, Project NENASC), Fundação de Apoio à Pesquisa do Estado de Santa Catarina (FAPESC), FINEP (Financiadora de Estudos e Projetos, IBN-Net \#01.06.0842-00), and INCT (Instituto Nacional de Ciência e Tecnologia) for Excitotoxicity and Neuroprotection. Josiel Mileno Mack, Marissa Giovanna Schamne, and Tuane Bazanella Sampaio received scholarship from CAPES or CNPq. Regina P. Markus and Rui Daniel Prediger are supported by research fellowships from CNPq.

\section{References}

[1] A. B. Lerner, J. D. Case, Y. Takahashi, T. H. Lee, and W. Mori, "Isolation of melatonin, the pineal gland factor that lightens melanocytes," Journal of the American Chemical Society, vol. 80, no. 10, p. $2587,1958$.

[2] R. J. Wurtman, J. Axelrod, and E. W. Chu, "Melatonin, a pineal substance: effect on the rat ovary," Science, vol. 141, no. 3577, pp. 277-278, 1963.

[3] J. Axelrod, R. J. Wurtman, and S. H. Snyder, "Control of hydroxyindole O-methyltransferase activity in the rat pineal," The Journal of Biological Chemistry, vol. 240, pp. 949-954, 1965. 
[4] A. Carrillo-Vico, P. J. Lardone, N. Álvarez-Śnchez, A. Rodrĩguez-Rodrĩguez, and J. M. Guerrero, "Melatonin: buffering the immune system," International Journal of Molecular Sciences, vol. 14, no. 4, pp. 8638-8683, 2013.

[5] R. P. Markus, E. Cecon, and M. A. Pires-Lapa, "Immunepineal axis: nuclear factor $\kappa \mathrm{B}(\mathrm{NF}-\mathrm{KB})$ mediates the shift in the melatonin source from pinealocytes to immune competent cells," International Journal of Molecular Sciences, vol. 14, no. 6, pp. 10979-10997, 2013.

[6] D. Acuña-Castroviejo, G. Escames, C. Venegas et al., "Extrapineal melatonin: sources, regulation, and potential functions," Cellular and Molecular Life Sciences, vol. 71, no. 16, pp. 29973025, 2014.

[7] E. Martins Jr., A. C. F. Ferreira, A. L. Skorupa, S. C. Afeche, J. Cipolla-Neto, and L. F. B. P. Costa Rosa, "Tryptophan consumption and indoleamines production by peritoneal cavity macrophages," Journal of Leukocyte Biology, vol. 75, no. 6, pp. 1116-1121, 2004.

[8] S. M. Muxel, M. A. Pires-Lapa, A. W. A. Monteiro et al., "NF- $\kappa$ B drives the synthesis of melatonin in RAW 264.7 macrophages by inducing the transcription of the arylalkylamine-Nacetyltransferase (AA-NAT) gene," PLoS ONE, vol. 7, no. 12, Article ID e52010, 2012.

[9] A. Conti, S. Conconi, E. Hertens, K. Skwarlo-Sonta, M. Markowska, and G. J. M. Maestroni, "Evidence for melatonin synthesis in mouse and human bone marrow cells," Journal of Pineal Research, vol. 28, no. 4, pp. 193-202, 2000.

[10] J. Stefulj, M. Hörtner, M. Ghosh et al., "Gene expression of the key enzymes of melatonin synthesis in extrapineal tissues of the rat," Journal of Pineal Research, vol. 30, no. 4, pp. 243-247, 2001.

[11] Y.-J. Liu, J. Zhuang, H.-Y. Zhu, Y.-X. Shen, Z.-L. Tan, and J.N. Zhou, "Cultured rat cortical astrocytes synthesize melatonin: absence of a diurnal rhythm," Journal of Pineal Research, vol. 43, no. 3, pp. 232-238, 2007.

[12] G. S. Kinker, S. M. Oba-Shinjo, C. E. Carvalho-Sousa et al., "Melatonergic system-based two-gene index is prognostic in human gliomas," Journal of Pineal Research, vol. 60, no. 1, pp. 84-94, 2016.

[13] G. A. Bubenik, "Thirty four years since the discovery of gastrointestinal melatonin," Journal of Physiology and Pharmacology, vol. 59, supplement 2, pp. 33-51, 2008.

[14] K. Sakaguchi, M. T. Itoh, N. Takahashi, W. Tarumi, and B. Ishizuka, "The rat oocyte synthesises melatonin," Reproduction, Fertility and Development, vol. 25, no. 4, pp. 674-682, 2013.

[15] D. Lanoix, H. Beghdadi, J. Lafond, and C. Vaillancourt, "Human placental trophoblasts synthesize melatonin and express its receptors," Journal of Pineal Research, vol. 45, no. 1, pp. 50-60, 2008.

[16] A. Soliman, A.-A. Lacasse, D. Lanoix, L. Sagrillo-Fagundes, V. Boulard, and C. Vaillancourt, "Placental melatonin system is present throughout pregnancy and regulates villous trophoblast differentiation," Journal of Pineal Research, vol. 59, no. 1, pp. 3846, 2015.

[17] G. N. Pontes, E. C. Cardoso, M. M. S. Carneiro-Sampaio, and R. P. Markus, "Pineal melatonin and the innate immune response: the TNF- $\alpha$ increase after cesarean section suppresses nocturnal melatonin production," Journal of Pineal Research, vol. 43, no. 4, pp. 365-371, 2007.

[18] V. Simonneaux and C. Ribelayga, "Generation of the melatonin endocrine message in mammals: a review of the complex regulation of melatonin synthesis by norepinephrine, peptides, and other pineal transmitters," Pharmacological Reviews, vol. 55, no. 2, pp. 325-395, 2003.

[19] D. Cazaméa-Catalan, L. Besseau, J. Falcón, and E. Magnanou, "The timing of Timezyme diversification in vertebrates," PLoS ONE, vol. 9, no. 12, Article ID el12380, 2014.

[20] K. J. Schippers and S. A. Nichols, "Deep, dark secrets of melatonin in animal evolution," Cell, vol. 159, no. 1, pp. 9-10, 2014.

[21] S. Park, Y. Byeon, H. Y. Lee, Y.-S. Kim, T. Ahn, and K. Back, "Cloning and characterization of a serotonin Nacetyltransferase from a gymnosperm, loblolly pine (Pinus taeda)," Journal of Pineal Research, vol. 57, no. 3, pp. 348-355, 2014.

[22] M. Møller and F. M. Baeres, "The anatomy and innervation of the mammalian pineal gland," Cell and Tissue Research, vol. 309, no. 1, pp. 139-150, 2002.

[23] C. Schomerus and H.-W. Korf, "Cholinergic signal transduction cascades in rat pinealocytes: functional and ontogenetic aspects," Reproduction Nutrition Development, vol. 39, no. 3, pp. 305-314, 1999.

[24] D. Villela, V. F. Atherino, L. D. S. Lima et al., "Modulation of pineal melatonin synthesis by glutamate involves paracrine interactions between pinealocytes and astrocytes through NF$\kappa \mathrm{B}$ activation," BioMed Research International, vol. 2013, Article ID 618432, 14 pages, 2013.

[25] H. Yu, S. G. Benitez, S. Jung et al., "GABAergic signaling in the rat pineal gland," Journal of Pineal Research, vol. 61, no. 1, pp. 69-81, 2016.

[26] R. P. Markus, Z. S. Ferreira, P. A. Fernandes, and E. Cecon, "The immune-pineal axis: a shuttle between endocrine and paracrine melatonin sources," Neuroimmunomodulation, vol. 14, no. 3-4, pp. 126-133, 2007.

[27] D. L. Terriff, C. L. Chik, D. M. Price, and A. K. Ho, "Proteasomal proteolysis in the adrenergic induction of arylalkylamine-Nacetyltransferase in rat pinealocytes," Endocrinology, vol. 146, no. 11, pp. 4795-4803, 2005.

[28] M. de Oliveira Tatsch-Dias, R. M. Levandovski, I. C. C. de Souza et al., "The concept of the immune-pineal axis tested in patients undergoing an abdominal hysterectomy," NeuroImmunoModulation, vol. 20, no. 4, pp. 205-212, 2013.

[29] P. A. C. M. Fernandes, B. Bothorel, D. Clesse et al., "Local corticosterone infusion enhances nocturnal pineal melatonin production in vivo," Journal of Neuroendocrinology, vol. 21, no. 2, pp. 90-97, 2009.

[30] C. Ribelayga, P. Pévet, and V. Simonneaux, "HIOMT drives the photoperiodic changes in the amplitude of the melatonin peak of the siberian hamster," American Journal of PhysiologyRegulatory Integrative and Comparative Physiology, vol. 278, no. 5, pp. R1339-R1345, 2000.

[31] T. Liu and J. Borjigin, "N-acetyltransferase is not the ratelimiting enzyme of melatonin synthesis at night," Journal of Pineal Research, vol. 39, no. 1, pp. 91-96, 2005.

[32] G. A. Bubenik, G. M. Brown, and L. J. Grota, "Immunohistological localization of melatonin in the rat digestive system," Experientia, vol. 33, no. 5, pp. 662-663, 1977.

[33] P. J. Lardone, A. Rubio, I. Cerrillo et al., "Blocking of melatonin synthesis and MT1 receptor impairs the activation of Jurkat T cells," Cellular and Molecular Life Sciences, vol. 67, no. 18, pp. 3163-3172, 2010.

[34] P. J. Lardone, J. M. Guerrero, J. M. Fernández-Santos, A. Rubio, I. Martín-Lacave, and A. Carrillo-Vico, "Melatonin synthesized 
by T lymphocytes as a ligand of the retinoic acid-related orphan receptor," Journal of Pineal Research, vol. 51, no. 4, pp. 454-462, 2011.

[35] M. C. Naranjo, J. M. Guerrero, A. Rubio et al., "Melatonin biosynthesis in the thymus of humans and rats," Cellular and Molecular Life Sciences, vol. 64, no. 6, pp. 781-790, 2007.

[36] A. Gómez-Corvera, I. Cerrillo, P. Molinero et al., "Evidence of immune system melatonin production by two pineal melatonin deficient mice, C57BL/6 and Swiss strains," Journal of Pineal Research, vol. 47, no. 1, pp. 15-22, 2009.

[37] S. da Silveira Cruz-Machado, C. E. Carvalho-Sousa, E. K. Tamura et al., "TLR4 and CD14 receptors expressed in rat pineal gland trigger NFKB pathway," Journal of Pineal Research, vol. 49, no. 2, pp. 183-192, 2010.

[38] S. da Silveira Cruz-Machado, L. Pinato, E. K. Tamura, C. E. Carvalho-Sousa, and R. P. Markus, "Glia-pinealocyte network: the paracrine modulation of melatonin synthesis by tumor necrosis factor (TNF)," PLoS ONE, vol. 7, no. 7, Article ID e40142, 2012.

[39] C. E. Carvalho-Sousa, S. da Silveira Cruz-Machado, K. E. Tamura et al., "Molecular basis for defining the pineal gland and pinealocytes as targets for tumor necrosis factor," Frontiers in Endocrinology, vol. 2, article 10, 2010.

[40] E. Cecon, P. A. Fernandes, L. Pinato, Z. S. Ferreira, and R. P. Markus, "Daily variation of constitutively activated nuclear factor kappa B (NFKB) in rat pineal gland," Chronobiology International, vol. 27, no. 1, pp. 52-67, 2010.

[41] M. A. Pires-Lapa, E. K. Tamura, E. M. A. Salustiano, and R. P. Markus, "Melatonin synthesis in human colostrum mononuclear cells enhances dectin-1-mediated phagocytosis by mononuclear cells," Journal of Pineal Research, vol. 55, no. 3, pp. 240-246, 2013.

[42] S. M. Muxel, M. F. Laranjeira-Silva, C. E. Carvalho-Sousa, L. M. Floeter-Winter, and R. P. Markus, "The RelA/cRel nuclear factor-kappaB (NF- $\kappa \mathrm{B})$ dimer, crucial for inflammation resolution, mediates the transcription of the key enzyme in melatonin synthesis in RAW 264.7 macrophages," Journal of Pineal Research, vol. 60, no. 4, pp. 394-404, 2016.

[43] E. K. Tamura, P. A. Fernandes, M. Marçola, S. D. S. CruzMachado, and R. P. Markus, "Long-lasting priming of endothelial cells by plasma melatonin levels," PLoS ONE, vol. 5, no. 11, Article ID e13958, 2010.

[44] M. Marçola, S. da Silveira Cruz-Machado, P. A. C. M. Fernandes, A. W. A. Monteiro, R. P. Markus, and E. K. Tamura, "Endothelial cell adhesiveness is a function of environmental lighting and melatonin level," Journal of Pineal Research, vol. 54, no. 2, pp. 162-169, 2013.

[45] B. de Luxán-Delgado, B. Caballero, Y. Potes et al., "Melatonin administration decreases adipogenesis in the liver of ob/ob mice through autophagy modulation," Journal of Pineal Research, vol. 56, no. 2, pp. 126-133, 2014.

[46] M. F. Laranjeira-Silva, R. A. Zampieri, S. M. Muxel, L. M. Floeter-Winter, and R. P. Markus, "Melatonin attenuates Leishmania (L.) amazonensis infection by modulating arginine metabolism," Journal of Pineal Research, vol. 59, no. 4, pp. 478487, 2015.

[47] P. A. Fernandes, E. K. Tamura, L. D’Argenio-Garcia et al., "Dual effect of catecholamines and corticosterone crosstalk on pineal gland melatonin synthesis," Neuroendocrinology, 2016.

[48] Z. S. Ferreira, P. A. C. M. Fernandes, D. Duma, J. Assreuy, M. C. W. Avellar, and R. P. Markus, "Corticosterone modulates noradrenaline-induced melatonin synthesis through inhibition of nuclear factor kappa B," Journal of Pineal Research, vol. 38, no. 3, pp. 182-188, 2005.

[49] R. Jockers, P. Delagrange, M. L. Dubocovich et al., "Update on melatonin receptors: IUPHAR Review 20," British Journal of Pharmacology, vol. 173, no. 18, pp. 2702-2725, 2016.

[50] M. L. Dubocovich and M. Markowska, "Functional MT ${ }_{1}$ and $\mathrm{MT}_{2}$ melatonin receptors in mammals," Endocrine, vol. 27, no. 2, pp. 101-110, 2005.

[51] M. Kamal, F. Gbahou, J.-L. Guillaume et al., "Convergence of melatonin and serotonin (5-HT) signaling at MT2/5- $\mathrm{HT}_{2} \mathrm{C}$ receptor heteromers," The Journal of Biological Chemistry, vol. 290, no. 18, pp. 11537-11546, 2015.

[52] L. Dufourny, A. Levasseur, M. Migaud et al., "GPR50 is the mammalian ortholog of Mellc: evidence of rapid evolution in mammals," BMC Evolutionary Biology, vol. 8, article 105, 2008.

[53] A. Levoye, J. Dam, M. A. Ayoub et al., "The orphan GPR50 receptor specifically inhibits MT1 melatonin receptor function through heterodimerization," The EMBO Journal, vol. 25, no. 13, pp. 3012-3023, 2006.

[54] J.-K. Jeong and S.-Y. Park, "Melatonin regulates the autophagic flux via activation of alpha-7 nicotinic acetylcholine receptors," Journal of Pineal Research, vol. 59, no. 1, pp. 24-37, 2015.

[55] D. K. Lahiri, "Melatonin affects the metabolism of the $\beta$ amyloid precursor protein in different cell types," Journal of Pineal Research, vol. 26, no. 3, pp. 137-146, 1999.

[56] N. Dragicevic, N. Copes, G. O’Neal-Moffitt et al., "Melatonin treatment restores mitochondrial function in Alzheimer's mice: a mitochondrial protective role of melatonin membrane receptor signaling," Journal of Pineal Research, vol. 51, no. 1, pp. 75-86, 2011.

[57] A. H. V. Schapira and C. W. Olanow, "Neuroprotection in Parkinson Disease: mysteries, myths, and misconceptions," Journal of the American Medical Association, vol. 291, no. 3, pp. 358-364, 2004.

[58] L. C. Manchester, A. Coto-Montes, J. A. Boga et al., "Melatonin: an ancient molecule that makes oxygen metabolically tolerable," Journal of Pineal Research, vol. 59, no. 4, pp. 403-419, 2015.

[59] B. Poeggeler, S. Saarela, R. J. Reiter et al., "Melatonin—a highly potent endogenous radical scavenger and electron donor: New aspects of the oxidation chemistry of this indole accessed in vitro," Annals of the New York Academy of Sciences, vol. 738, pp. 419-420, 1994.

[60] R. Hardeland, D.-X. Tan, and R. J. Reiter, "Kynuramines, metabolites of melatonin and other indoles: the resurrection of an almost forgotten class of biogenic amines," Journal of Pineal Research, vol. 47, no. 2, pp. 109-126, 2009.

[61] S.-I. Choi, S. Dadakhujaev, H. Ryu, T. Im Kim, and E. K. Kim, "Melatonin protects against oxidative stress in granular corneal dystrophy type 2 corneal fibroblasts by mechanisms that involve membrane melatonin receptors," Journal of Pineal Research, vol. 51, no. 1, pp. 94-103, 2011.

[62] G. O’Neal-Moffitt, V. Delic, P. C. Bradshaw, and J. Olcese, "Prophylactic melatonin significantly reduces Alzheimer's neuropathology and associated cognitive deficits independent of antioxidant pathways in A $\beta \mathrm{PP}($ swe)/PS1 mice," Molecular Neurodegeneration, vol. 10, no. 1, article 27, 2015.

[63] D. G. Franco and R. P. Markus, "The cellular state determines the effect of melatonin on the survival of mixed cerebellar cell culture," PLoS ONE, vol. 9, no. 9, Article ID e106332, 2014. 
[64] L. Pinato, S. da Silveira Cruz-Machado, D. G. Franco et al., "Selective protection of the cerebellum against intracerebroventricular LPS is mediated by local melatonin synthesis," Brain Structure \& Function, vol. 220, no. 2, pp. 827-840, 2015.

[65] Y. Dong, C. Fan, W. Hu et al., "Melatonin attenuated early brain injury induced by subarachnoid hemorrhage via regulating NLRP3 inflammasome and apoptosis signaling," Journal of Pineal Research, vol. 60, no. 3, pp. 253-262, 2016.

[66] F. Ortiz, D. Acuña-Castroviejo, C. Doerrier et al., "Melatonin blunts the mitochondrial/NLRP3 connection and protects against radiation-induced oral mucositis," Journal of Pineal Research, vol. 58, no. 1, pp. 34-49, 2015.

[67] Z. Feng, Y. Chang, Y. Cheng et al., "Melatonin alleviates behavioral deficits associated with apoptosis and cholinergic system dysfunction in the APP 695 transgenic mouse model of Alzheimer's disease," Journal of Pineal Research, vol. 37, no. 2, pp. 129-136, 2004.

[68] R. P. Markus, C. L. M. Silva, D. G. Franco, E. M. Barbosa Jr., and Z. S. Ferreira, "Is modulation of nicotinic acetylcholine receptors by melatonin relevant for therapy with cholinergic drugs?" Pharmacology \& Therapeutics, vol. 126, no. 3, pp. 251262, 2010.

[69] E. Parada, I. Buendia, R. León et al., "Neuroprotective effect of melatonin against ischemia is partially mediated by alpha7 nicotinic receptor modulation and HO-1 overexpression," Journal of Pineal Research, vol. 56, no. 2, pp. 204-212, 2014.

[70] E. Savaskan, M. A. Ayoub, R. Ravid et al., "Reduced hippocampal MT2 melatonin receptor expression in Alzheimer's disease," Journal of Pineal Research, vol. 38, no. 1, pp. 10-16, 2005.

[71] P. Brunner, N. Sözer-Topcular, R. Jockers et al., "Pineal and cortical melatonin receptors MT1 and MT2 are decreased in Alzheimer's disease," European Journal of Histochemistry, vol. 50, no. 4, pp. 311-316, 2006.

[72] Y.-H. Wu, J.-N. Zhou, J. Van Heerikhuize, R. Jockers, and D. F. Swaab, "Decreased MT1 melatonin receptor expression in the suprachiasmatic nucleus in aging and Alzheimer's disease," Neurobiology of Aging, vol. 28, no. 8, pp. 1239-1247, 2007.

[73] N. Adi, D. C. Mash, Y. Ali, C. Singer, L. Shehadeh, and S. Papapetropoulos, "Melatonin MT1 and MT2 receptor expression in Parkinson's disease," Medical Science Monitor, vol. 16, no. 2, pp. BR61-BR67, 2010.

[74] K. Uchida, N. Okamoto, K. Ohara, and Y. Morita, "Daily rhythm of serum melatonin in patients with dementia of the degenerate type," Brain Research, vol. 717, no. 1-2, pp. 154-159, 1996.

[75] J.-N. Zhou, R.-Y. Liu, W. Kamphorst, M. A. Hofman, and D. F. Swaab, "Early neuropathological Alzheimer's changes in aged individuals are accompanied by decreased cerebrospinal fluid melatonin levels," Journal of Pineal Research, vol. 35, no. 2, pp. 125-130, 2003.

[76] A. Videnovic, D. P. Breen, R. A. Barker, and P. C. Zee, "The central clock in patients with Parkinson disease-reply," JAMA Neurology, vol. 71, no. 11, pp. 1456-1457, 2014.

[77] E. Cecon, M. Chen, M. Marçola, P. A. C. Fernandes, R. Jockers, and R. P. Markus, "Amyloid $\beta$ peptide directly impairs pineal gland melatonin synthesis and melatonin receptor signaling through the ERK pathway," FASEB Journal, vol. 29, no. 6, pp. 2566-2582, 2015.

[78] A. G. Wade, M. Farmer, G. Harari et al., "Add-on prolongedrelease melatonin for cognitive function and sleep in mild to moderate Alzheimer's disease: a 6-month, randomized, placebo-controlled, multicenter trial," Clinical Interventions in Aging, vol. 9, pp. 947-961, 2014.
[79] S. Rosales-Corral, D.-X. Tan, R. J. Reiter et al., "Orally administered melatonin reduces oxidative stress and proinflammatory cytokines induced by amyloid- $\beta$ peptide in rat brain: a comparative, in vivo study versus vitamin C and E," Journal of Pineal Research, vol. 35, no. 2, pp. 80-84, 2003.

[80] N. A. Aziz, H. Pijl, M. Frölich et al., "Delayed onset of the diurnal melatonin rise in patients with Huntington's disease," Journal of Neurology, vol. 256, no. 12, pp. 1961-1965, 2009.

[81] M. F. Farez, I. D. Mascanfroni, S. P. Méndez-Huergo et al., "Melatonin contributes to the seasonality of multiple sclerosis relapses," Cell, vol. 162, no. 6, pp. 1338-1352, 2015.

[82] T. Ritzenthaler, N. Nighoghossian, J. Berthiller et al., "Nocturnal urine melatonin and 6-sulphatoxymelatonin excretion at the acute stage of ischaemic stroke," Journal of Pineal Research, vol. 46, no. 3, pp. 349-352, 2009.

[83] A. L. Morera-Fumero and P. Abreu-Gonzalez, "Role of melatonin in schizophrenia," International Journal of Molecular Sciences, vol. 14, no. 5, pp. 9037-9050, 2013.

[84] E. Fertl, E. Auff, A. Doppelbauer, and F. Waldhauser, "Circadian secretion pattern of melatonin in de novo Parkinsonian patients: evidence for phase-shifting properties of 1-dopa," Journal of Neural Transmission-Parkinson's Disease and Dementia Section, vol. 5, no. 3, pp. 227-234, 1993.

[85] E. Fertl, E. Auff, A. Doppelbauer, and F. Waldhauser, "Circadian secretion pattern of melatonin in Parkinson's disease," Journal of Neural Transmission-Parkinson's Disease and Dementia Section, vol. 3, no. 1, pp. 41-47, 1991.

[86] R. Bordet, D. Devos, S. Brique et al., "Study of circadian melatonin secretion pattern at different stages of Parkinson's disease," Clinical Neuropharmacology, vol. 26, no. 2, pp. 65-72, 2003.

[87] A. Videnovic, C. Noble, K. J. Reid et al., "Circadian melatonin rhythm and excessive daytime sleepiness in Parkinson disease," JAMA Neurology, vol. 71, no. 4, pp. 463-469, 2014.

[88] H. Chen, E. Schernhammer, M. A. Schwarzschild, and A. Ascherio, "A prospective study of night shift work, sleep duration, and risk of Parkinson's disease," American Journal of Epidemiology, vol. 163, no. 8, pp. 726-730, 2006.

[89] J. Gao, X. Huang, Y. Park et al., "Daytime napping, nighttime sleeping, and parkinson disease," American Journal of Epidemiology, vol. 173, no. 9, pp. 1032-1038, 2011.

[90] C. Venegas, J. A. García, G. Escames et al., "Extrapineal melatonin: analysis of its subcellular distribution and daily fluctuations," Journal of Pineal Research, vol. 52, no. 2, pp. 217227, 2012.

[91] M. A. Seifman, A. A. Adamides, P. N. Nguyen et al., "Endogenous melatonin increases in cerebrospinal fluid of patients after severe traumatic brain injury and correlates with oxidative stress and metabolic disarray," Journal of Cerebral Blood Flow and Metabolism, vol. 28, no. 4, pp. 684-696, 2008.

[92] J. Leston, C. Harthé, C. Mottolese, P. Mertens, M. Sindou, and B. Claustrat, "Is pineal melatonin released in the third ventricle in humans? A study in movement disorders," Neurochirurgie, vol. 61, no. 2-3, pp. 85-89, 2015.

[93] C. Legros, D. Chesneau, J. A. Boutin, C. Barc, and B. Malpaux, "Melatonin from cerebrospinal fluid but not from blood reaches sheep cerebral tissues under physiological conditions," Journal of Neuroendocrinology, vol. 26, no. 3, pp. 151-163, 2014.

[94] S. Singh and M. Dikshit, "Apoptotic neuronal death in Parkinson's disease: involvement of nitric oxide," Brain Research Reviews, vol. 54, no. 2, pp. 233-250, 2007. 
[95] A. Samii, J. G. Nutt, and B. R. Ransom, "Parkinson's disease," The Lancet, vol. 363, no. 9423, pp. 1783-1793, 2004.

[96] D. Burch and F. Sheerin, "Parkinson's disease," Thye Lancet, vol. 365, no. 9459, pp. 622-627, 2005.

[97] Z. Mansouri, M. Sabetkasaei, F. Moradi, F. Masoudnia, and A. Ataie, "Curcumin has neuroprotection effect on homocysteine rat model of Parkinson," Journal of Molecular Neuroscience, vol. 47, no. 2, pp. 234-242, 2012.

[98] J. Massano, "Parkinson's disease: a clinical update," Acta Medica Portuguesa, vol. 24, no. 4, pp. 827-834, 2011.

[99] R. J. Dinis-Oliveira, F. Remião, H. Carmo et al., "Paraquat exposure as an etiological factor of Parkinson's disease," NeuroToxicology, vol. 27, no. 6, pp. 1110-1122, 2006.

[100] C. Rodríguez-Nogales, E. Garbayo, M. M. Carmona-Abellán, M. R. Luquin, and M. J. Blanco-Prieto, "Brain aging and Parkinson's disease: new therapeutic approaches using drug delivery systems," Maturitas, vol. 84, pp. 25-31, 2016.

[101] P. Michel, E. Hirsch, and S. Hunot, "Understanding dopaminergic cell death pathways in parkinson disease," Neuron, vol. 90, no. 4, pp. 675-691, 2016

[102] A. L. McCormack, M. Thiruchelvam, A. B. Manning-Bog et al., "Environmental risk factors and Parkinson's disease: selective degeneration of nigral dopaminergic neurons caused by the herbicide paraquat," Neurobiology of Disease, vol. 10, no. 2, pp. 119-127, 2002.

[103] A. Wood-Kaczmar, S. Gandhi, and N. W. Wood, "Understanding the molecular causes of Parkinson's disease," Trends in Molecular Medicine, vol. 12, no. 11, pp. 521-528, 2006.

[104] D. Sulzer, "Multiple hit hypotheses for dopamine neuron loss in Parkinson's disease," Trends in Neurosciences, vol. 30, no. 5, pp. 244-250, 2007.

[105] R. M. Ransohoff, "How neuroinflammation contributes to neurodegeneration," Science, vol. 353, no. 6301, pp. 777-783, 2016.

[106] A. De Virgilio, A. Greco, G. Fabbrini et al., "Parkinson's disease: autoimmunity and neuroinflammation," Autoimmunity Reviews, vol. 15, no. 10, pp. 1005-1011, 2016.

[107] P. Jenner and C. W. Olanow, "The pathogenesis of cell death in Parkinson's disease," Neurology, vol. 66, no. 10, pp. S24-S30, 2006.

[108] N. Singh, V. Pillay, and Y. E. Choonara, "Advances in the treatment of Parkinson's disease," Progress in Neurobiology, vol. 81, no. 1, pp. 29-44, 2007.

[109] V. Dias, E. Junn, and M. M. Mouradian, "The role of oxidative stress in parkinson's disease," Journal of Parkinson's Disease, vol. 3, no. 4, pp. 461-491, 2013.

[110] S. Klongpanichapak, P. Phansuwan-Pujito, M. Ebadi, and P. Govitrapong, "Melatonin protects SK-N-SH neuroblastoma cells from amphetamine-induced neurotoxicity," Journal of Pineal Research, vol. 43, no. 1, pp. 65-73, 2007.

[111] A. F. G. Leentjens, K. Dujardin, L. Marsh, P. Martinez-Martin, I. H. Richard, and S. E. Starkstein, "Anxiety and motor fluctuations in Parkinson's disease: a cross-sectional observational study," Parkinsonism and Related Disorders, vol. 18, no. 10, pp. 1084-1088, 2012.

[112] A. Sidhu, C. Wersinger, and P. Vernier, " $\alpha$-Synuclein regulation of the dopaminergic transporter: a possible role in the pathogenesis of Parkinson's disease," FEBS Letters, vol. 565, no. 1-3, pp. 1-5, 2004.

[113] B. Dehay and P. O. Fernagut, "Alpha-synuclein-based models of Parkinson's disease," Revue Neurologique, vol. 172, no. 6-7, pp. 371-378, 2016.
[114] E. Altschuler, "Aluminium-containing antacids as a cause of idiopathic Parkinson's disease," Medical Hypotheses, vol. 53, no. 1, pp. 22-23, 1999.

[115] L. E. Davis and J. C. Adair, "Parkinsonism from methanol poisoning: benefit from treatment with anti-Parkinson drugs," Movement Disorders, vol. 14, no. 3, pp. 520-522, 1999.

[116] S. H. Snyder and R. J. D’Amato, "MPTP: a neurotoxin relevant to the pathophysiology of Parkinson's disease: The 1985 George C. Cotzias Lecture," Neurology, vol. 36, no. 2, pp. 250-258, 1986.

[117] B. I. Giasson and V. M.-Y. Lee, "A new link between pesticides and Parkinson's disease," Nature Neuroscience, vol. 3, no. 12, pp. $1227-1228,2000$

[118] A. J. Lees, J. Hardy, and T. Revesz, "Parkinson's disease," The Lancet, vol. 373, no. 9680, pp. 2055-2066, 2009.

[119] B. Bruguerolle and N. Simon, "Biologic rhythms and Parkinson's disease: a chronopharmacologic approach to considering fluctuations in function," Clinical Neuropharmacology, vol. 25, no. 4, pp. 194-201, 2002.

[120] G. L. Willis, "Parkinson's disease as a neuroendocrine disorder of circadian function: dopamine-melatonin imbalance and the visual system in the genesis and progression of the degenerative process," Reviews in the Neurosciences, vol. 19, no. 4-5, pp. 245 316, 2008.

[121] B. F. Boeve, M. H. Silber, T. J. Ferman et al., "Clinicopathologic correlations in 172 cases of rapid eye movement sleep behavior disorder with or without a coexisting neurologic disorder," Sleep Medicine, vol. 14, no. 8, pp. 754-762, 2013.

[122] D. P. Breen, R. Vuono, U. Nawarathna et al., "Sleep and circadian rhythm regulation in early Parkinson disease," JAMA Neurology, vol. 71, no. 5, pp. 589-595, 2014.

[123] K. R. Chaudhuri, D. G. Healy, and A. H. V. Schapira, "Nonmotor symptoms of Parkinson's disease: diagnosis and management," Lancet Neurology, vol. 5, no. 3, pp. 235-245, 2006.

[124] K. R. Chaudhuri and A. H. Schapira, "Non-motor symptoms of Parkinson's disease: dopaminergic pathophysiology and treatment," The Lancet Neurology, vol. 8, no. 5, pp. 464-474, 2009.

[125] A. Bonito-Oliva, D. Masini, and G. Fisone, "A mouse model of non-motor symptoms in Parkinson's disease: focus on pharmacological interventions targeting affective dysfunctions," Frontiers in Behavioral Neuroscience, vol. 8, article 290, 2014.

[126] H. Braak, K. Del Tredici, U. Rüb, R. A. I. De Vos, E. N. H. Jansen Steur, and E. Braak, "Staging of brain pathology related to sporadic Parkinson's disease," Neurobiology of Aging, vol. 24, no. 2, pp. 197-211, 2003.

[127] A. Roy and K. Pahan, "Prospects of statins in Parkinson disease," The Neuroscientist, vol. 17, no. 3, pp. 244-255, 2011.

[128] P. K. Sonsalla, L.-Y. Wong, S. L. Harris et al., "Delayed caffeine treatment prevents nigral dopamine neuron loss in a progressive rat model of Parkinson's disease," Experimental Neurology, vol. 234, no. 2, pp. 482-487, 2012.

[129] S. Maranis, S. Tsouli, and S. Konitsiotis, "Treatment of motor symptoms in advanced Parkinson's disease: a practical approach," Progress in Neuro-Psychopharmacology \& Biological Psychiatry, vol. 35, no. 8, pp. 1795-1807, 2011.

[130] J. Castro-Hernández, D. Afonso-Oramas, I. Cruz-Muros et al., "Prolonged treatment with pramipexole promotes physical interaction of striatal dopamine D3 autoreceptors with dopamine transporters to reduce dopamine uptake," Neurobiology of Disease, vol. 74, pp. 325-335, 2015.

[131] S. Burton, S. Daya, and B. Potgieter, "Melatonin modulates apomorphine-induced rotational behaviour," Experientia, vol. 47, no. 5, pp. 466-469, 1991. 
[132] J. C. Mayo, R. M. Sainz, H. Uria, I. Antolin, M. M. Esteban, and C. Rodriguez, "Melatonin prevents apoptosis induced by 6-hydroxydopamine in neuronal cells: implications for Parkinson's disease," Journal of Pineal Research, vol. 24, no. 3, pp. 179192, 1998.

[133] W. S. Joo, B. K. Jin, C. W. Park, S. H. Maeng, and Y. S. Kim, "Melatonin increases striatal dopaminergic function in 6OHDA-lesioned rats," NeuroReport, vol. 9, no. 18, pp. 4123-4126, 1998.

[134] J. C. Mayo, R. M. Sainz, I. Antolín, and C. Rodriguez, "Ultrastructural confirmation of neuronal protection by melatonin against the neurotoxin 6-hydroxydopamine cell damage," Brain Research, vol. 818, no. 2, pp. 221-227, 1999.

[135] F. Dabbeni-Sala, S. Di Santo, D. Franceschini, S. D. Skaper, and P. Giusti, "Melatonin protects against 6-OHDA-induced neurotoxicity in rats: a role for mitochondrial complex I activity," The FASEB Journal, vol. 15, no. 1, pp. 164-170, 2001.

[136] L. M. V. Aguiar, S. M. M. Vasconcelos, F. C. F. Sousa, and G. S. B. Viana, "Melatonin reverses neurochemical alterations induced by 6-OHDA in rat striatum," Life Sciences, vol. 70, no. 9, pp. 1041-1051, 2002.

[137] B. Chetsawang, P. Govitrapong, and M. Ebadi, "The neuroprotective effect of melatonin against the induction of c-Jun phosphorylation by 6-hydroxydopamine on SK-N-SH cells," Neuroscience Letters, vol. 371, no. 2-3, pp. 205-208, 2004.

[138] R. Sharma, C. R. McMillan, C. C. Tenn, and L. P. Niles, "Physiological neuroprotection by melatonin in a 6-hydroxydopamine model of Parkinson's disease," Brain Research, vol. 1068, no. 1, pp. 230-236, 2006.

[139] S. Singh, R. Ahmed, R. K. Sagar, and B. Krishana, "Neuroprotection of the nigrostriatal dopaminergic neurons by melatonin in hemiparkinsonium rat," Indian Journal of Medical Research, vol. 124, no. 4, pp. 419-426, 2006.

[140] A. L. Gutierrez-Valdez, V. Anaya-Martínez, J. L. OrdoñezLibrado et al., "Effect of chronic L-dopa or melatonin treatments after dopamine deafferentation in rats: dyskinesia, motor performance, and cytological analysis," ISRN Neurology, vol. 2012, Article ID 360379, 16 pages, 2012.

[141] F. B. Yildirim, O. Ozsoy, G. Tanriover et al., "Mechanism of the beneficial effect of melatonin in experimental Parkinson's disease," Neurochemistry International, vol. 79, pp. 1-11, 2014.

[142] Y. S. Kim, W. S. Joo, B. K. Jin, Y. H. Cho, H. H. Baik, and C. W. Park, "Melatonin protects 6-OHDA-induced neuronal death of nigrostriatal dopaminergic system," NeuroReport, vol. 9, no. 10, pp. 2387-2390, 1998.

[143] O. Ozsoy, F. B. Yildirim, E. Ogut et al., "Melatonin is protective against 6-hydroxydopamine-induced oxidative stress in a hemiparkinsonian rat model," Free Radical Research, vol. 49, no. 8, pp. 1004-1014, 2015.

[144] B. K. Jin, D. Y. Shin, M. Y. Jeong et al., "Melatonin protects nigral dopaminergic neurons from 1-methyl-4- phenylpyridinium (MPP+) neurotoxicity in rats," Neuroscience Letters, vol. 245, no. 2, pp. 61-64, 1998.

[145] E. Absi, A. Ayala, A. Machado, and J. Parrado, "Protective effect of melatonin against the 1-methyl-4-phenylpyridiniuminduced inhibition of complex I of the mitochondrial respiratory chain," Journal of Pineal Research, vol. 29, no. 1, pp. 40-47, 2000.

[146] T. C. Shur, I. C. Jih, H. H. Mei, and E. I-Chian Li, "Melatonin attenuates $\mathrm{MPP}^{+}$-induced neurodegeneration and glutathione impairment in the nigrostriatal dopaminergic pathway," Journal of Pineal Research, vol. 32, no. 4, pp. 262-269, 2002.
[147] L.-J. Chen, Y.-Q. Gao, X.-J. Li, D.-H. Shen, and F.-Y. Sun, "Melatonin protects against MPTP/MPP ${ }^{+}$-induced mitochondrial DNA oxidative damage in vivo and in vitro," Journal of Pineal Research, vol. 39, no. 1, pp. 34-42, 2005.

[148] D. Alvira, M. Tajes, E. Verdaguer et al., "Inhibition of the cdk5/p25 fragment formation may explain the antiapoptotic effects of melatonin in an experimental model of Parkinson's disease," Journal of Pineal Research, vol. 40, no. 3, pp. 251-258, 2006.

[149] J. Chetsawang, P. Govitrapong, and B. Chetsawang, "Melatonin inhibits MPP+-induced caspase-mediated death pathway and DNA fragmentation factor-45 cleavage in SK-N-SH cultured cells," Journal of Pineal Research, vol. 43, no. 2, pp. 115-120, 2007.

[150] J.-Y. Huang, Y.-T. Hong, and J.-I. Chuang, "Fibroblast growth factor 9 prevents MPP+-induced death of dopaminergic neurons and is involved in melatonin neuroprotection in vivo and in vitro," Journal of Neurochemistry, vol. 109, no. 5, pp. 14001412, 2009.

[151] D. Acuña-Castroviejo, A. Coto-Montes, M. G. Monti, G. G. Ortiz, and R. J. Reiter, "Melatonin is protective against MPTPinduced striatal and hippocampal lesions," Life Sciences, vol. 60, no. 2, pp. Pl23-Pl29, 1996.

[152] H. Khaldy, G. Escames, J. León, L. Bikjdaouene, and D. AcuñaCastroviejo, "Synergistic effects of melatonin and deprenyl against MPTP-induced mitochondrial damage and DA depletion," Neurobiology of Aging, vol. 24, no. 3, pp. 491-500, 2003.

[153] V. Tapias, G. Escames, L. C. López et al., "Melatonin and its brain metabolite $\mathrm{N}^{1}$-acetyl-5-methoxykynuramine prevent mitochondrial nitric oxide synthase induction in Parkinsonian mice," Journal of Neuroscience Research, vol. 87, no. 13, pp. 30023010, 2009.

[154] R. Niranjan, C. Nath, and R. Shukla, "The mechanism of action of MPTP-induced neuroinflammation and its modulation by melatonin in rat astrocytoma cells, C6," Free Radical Research, vol. 44, no. 11, pp. 1304-1316, 2010.

[155] G. Patki and Y.-S. Lau, "Melatonin protects against neurobehavioral and mitochondrial deficits in a chronic mouse model of Parkinson's disease," Pharmacology Biochemistry and Behavior, vol. 99, no. 4, pp. 704-711, 2011.

[156] S. A. Zaitone, L. N. Hammad, and N. E. Farag, "Antioxidant potential of melatonin enhances the response to L-dopa in 1-methyl 4-phenyl 1,2,3,6-tetrahydropyridine-parkinsonian mice," Pharmacological Reports, vol. 65, no. 5, pp. 1213-1226, 2013.

[157] A. Naskar, V. Prabhakar, R. Singh, D. Dutta, and K. P. Mohanakumar, "Melatonin enhances L-DOPA therapeutic effects, helps to reduce its dose, and protects dopaminergic neurons in 1-methyl-4-phenyl-1,2,3,6-tetrahydropyridine-induced parkinsonism in mice," Journal of Pineal Research, vol. 58, no. 3, pp. 262-274, 2015.

[158] M. E. Díaz-Casado, E. Lima, J. A. García et al., "Melatonin rescues zebrafish embryos from the parkinsonian phenotype restoring the parkin/PINK1/DJ-1/MUL1 network," Journal of Pineal Research, vol. 61, no. 1, pp. 96-107, 2016.

[159] H. Coulom and S. Birman, "Chronic exposure to rotenone models sporadic Parkinson's disease in Drosophila melanogaster," The Journal of Neuroscience, vol. 24, no. 48, pp. 10993-10998, 2004.

[160] K. S. Saravanan, K. M. Sindhu, and K. P. Mohanakumar, "Melatonin protects against rotenone-induced oxidative stress in a hemiparkinsonian rat model," Journal of Pineal Research, vol. 42, no. 3, pp. 247-253, 2007. 
[161] T. B. Bassani, R. W. Gradowski, T. Zaminelli et al., "Neuroprotective and antidepressant-like effects of melatonin in a rotenone-induced Parkinson's disease model in rats," Brain Research, vol. 1593, pp. 95-105, 2014.

[162] C. H. Carriere, N. H. Kang, and L. P. Niles, "Chronic lowdose melatonin treatment maintains nigrostriatal integrity in an intrastriatal rotenone model of Parkinson's disease," Brain Research, vol. 1633, pp. 115-125, 2016.

[163] M. Ishido, "Melatonin inhibits maneb-induced aggregation of $\alpha$-synuclein in rat pheochromocytoma cells," Journal of Pineal Research, vol. 42, no. 2, pp. 125-130, 2007.

[164] N. K. Singhal, G. Srivastava, D. K. Patel, S. K. Jain, and M. P. Singh, "Melatonin or silymarin reduces maneb- and paraquatinduced Parkinson's disease phenotype in the mouse," Journal of Pineal Research, vol. 50, no. 2, pp. 97-109, 2011.

[165] J. M. Brito-Armas, V. Baekelandt, J. R. Castro-Hernández, T. González-Hernández, M. Rodríguez, and R. C. Fuentes, "Melatonin prevents dopaminergic cell loss induced by lentiviral vectors expressing A30P mutant alpha-synuclein," Histology and Histopathology, vol. 28, no. 8, pp. 999-1006, 2013.

[166] Q. Wan, H.-Y. Man, F. Liu et al., "Differential modulation of GABAA receptor function by Mella and Mellb receptors," Nature Neuroscience, vol. 2, no. 5, pp. 401-403, 1999.

[167] M. V. Hogan, Y. El-Sherif, and A. Wieraszko, "The modulation of neuronal activity by melatonin: in vitro studies on mouse hippocampal slices," Journal of Pineal Research, vol. 30, no. 2, pp. 87-96, 2001.

[168] Y. El-Sherif, P. Witt-Enderby, P.-K. Li, J. Tesoriero, M. V. Hogan, and A. Wieraszko, "The actions of a charged melatonin receptor ligand, TMEPI, and an irreversible MT2 receptor agonist, BMNEP, on mouse hippocampal evoked potentials in vitro," Life Sciences, vol. 75, no. 26, pp. 3147-3156, 2004.

[169] L. M. Wang, N. A. Suthana, D. Chaudhury, D. R. Weaver, and C. S. Colwell, "Melatonin inhibits hippocampal long-term potentiation," The European Journal of Neuroscience, vol. 22, no. 9, pp. 2231-2237, 2005.

[170] J. Larson, R. E. Jessen, T. Uz et al., "Impaired hippocampal longterm potentiation in melatonin $\mathrm{MT}_{2}$ receptor-deficient mice," Neuroscience Letters, vol. 393, no. 1, pp. 23-26, 2006.

[171] G. O’Neal-Moffitt, J. Pilli, S. S. Kumar, and J. Olcese, “Genetic deletion of MT1/MT2 melatonin receptors enhances murine cognitive and motor performance," Neuroscience, vol. 277, pp. 506-521, 2014.

[172] P. Golus and M. G. King, "The effects of melatonin on open field behavior," Pharmacology, Biochemistry and Behavior, vol. 15, no. 6, pp. 883-885, 1981.

[173] D. A. Golombek, M. Martini, and D. P. Cardinali, "Melatonin as an anxiolytic in rats: time dependence and interaction with the central GABAergic system," European Journal of Pharmacology, vol. 237, no. 2-3, pp. 231-236, 1993.

[174] G. Pierrefiche, R. Zerbib, and H. Laborit, "Anxiolytic activity of melatonin in mice: involvement of benzodiazepine receptors," Research Communications in Chemical Pathology and Pharmacology, vol. 82, no. 2, pp. 131-142, 1993.

[175] E. B. Naranjo-Rodriguez, A. O. Osornio, E. HernandezAvitia, V. Mendoza-Fernandez, and A. Escobar, "Anxiolyticlike actions of melatonin, 5-metoxytryptophol, 5hydroxytryptophol and benzodiazepines on a conflict procedure," Progress in Neuro-Psychopharmacology and Biological Psychiatry, vol. 24, no. 1, pp. 117-129, 2000.

[176] C. Kopp, E. Vogel, M.-C. Rettori, P. Delagrange, and R. Misslin, "Anxiolytic-like properties of melatonin receptor agonists in mice: involvement of $\mathrm{mtl}$ and/or MT2 receptors in the regulation of emotional responsiveness," Neuropharmacology, vol. 39, no. 10 , pp. 1865-1871, 2000.

[177] M. J. Millan, M. Brocco, A. Gobert, and A. Dekeyne, "Anxiolytic properties of agomelatine, an antidepressant with melatoninergic and serotonergic properties: role of 5-HT2C receptor blockade," Psychopharmacology, vol. 177, no. 4, pp. 448-458, 2005.

[178] M. Papp, E. Litwa, P. Gruca, and E. Mocaër, "Anxiolytic-like activity of agomelatine and melatonin in three animal models of anxiety," Behavioural Pharmacology, vol. 17, no. 1, pp. 9-18, 2006.

[179] F. Loiseau, C. Le Bihan, M. Hamon, and M.-H. Thiébot, "Effects of melatonin and agomelatine in anxiety-related procedures in rats: Interaction with diazepam," European Neuropsychopharmacology, vol. 16, no. 6, pp. 417-428, 2006.

[180] S.-W. Tian, M. Laudon, L. Han et al., "Antidepressant- and anxiolytic effects of the novel melatonin agonist Neu-P11 in rodent models," Acta Pharmacologica Sinica, vol. 31, no. 7, pp. 775-783, 2010.

[181] F. Z. El Mrabet, S. Ouaaki, A. Mesfioui, A. El Hessni, and A. Ouichou, "Pinealectomy and exogenous melatonin regulate anxiety-like and depressive-like behaviors in male and female wistar rats," Neuroscience \& Medicine, vol. 3, pp. 394-403, 2012.

[182] R. Ochoa-Sanchez, Q. Rainer, S. Comai et al., "Anxiolytic effects of the melatonin MT2 receptor partial agonist UCM765: comparison with melatonin and diazepam," Progress in NeuroPsychopharmacology and Biological Psychiatry, vol. 39, no. 2, pp. 318-325, 2012.

[183] G. H. Kim, J. E. Kim, S. J. Rhie, and S. Yoon, "The role of oxidative stress in neurodegenerative diseases," Experimental Neurobiology, vol. 24, no. 4, pp. 325-340, 2015.

[184] V. Jackson-Lewis, J. Blesa, and S. Przedborski, "Animal models of Parkinson's disease," Parkinsonism and Related Disorders, vol. 18, no. 1, pp. S183-S185, 2012.

[185] U. Ungerstedt, "6-hydroxy-dopamine induced degeneration of central monoamine neurons," European Journal of Pharmacology, vol. 5, no. 1, pp. 107-110, 1968.

[186] J. Bové, D. Prou, C. Perier, and S. Przedborski, "Toxin-induced models of Parkinson's disease," NeuroRx, vol. 2, no. 3, pp. 484494, 2005.

[187] J. S. Mendez and B. W. Finn, "Use of 6 hydroxydopamine to create lesions in catecholamine neurons in rats," Journal of Neurosurgery, vol. 42, no. 2, pp. 166-173, 1975.

[188] R. J. Reiter, D. X. Tan, and A. Galano, "Melatonin: exceeding expectations," Physiology, vol. 29, no. 5, pp. 325-333, 2014.

[189] J. W. Langston, P. Ballard, J. W. Tetrud, and I. Irwin, "Chronic parkinsonism in humans due to a product of meperidineanalog synthesis," Science, vol. 219, no. 4587, pp. 979-980, 1983.

[190] H. Mochizuki, N. Nakamura, K. Nishi, and Y. Mizuno, "Apoptosis is induced by 1-methyl-4-phenylpyridinium ion (MPP+) in ventral mesencephalic-striatal co-culture in rat," Neuroscience Letters, vol. 170, no. 1, pp. 191-194, 1994.

[191] H. Khaldy, G. Escames, J. León, F. Vives, J. D. Luna, and D. Acuña-Castroviejo, "Comparative effects of melatonin, Ldeprenyl, trolox and ascorbate in the suppression of hydroxyl radical formation during dopamine autoxidation in vitro," Journal of Pineal Research, vol. 29, no. 2, pp. 100-107, 2000.

[192] C. F. Ibáñez and J.-O. Andressoo, “Biology of GDNF and its receptors-relevance for disorders of the central nervous system," Neurobiology of Disease, 2016. 
[193] K. J. Armstrong and L. P. Niles, "Induction of GDNF mRNA expression by melatonin in rat C6 glioma cells," NeuroReport, vol. 13, no. 4, pp. 473-475, 2002.

[194] L. P. Niles, K. J. Armstrong, L. M. Rincón Castro et al., "Neural stem cells express melatonin receptors and neurotrophic factors: colocalization of the MT1 receptor with neuronal and glial markers," BMC Neuroscience, vol. 5, article 41, 2004.

[195] Y. P. Tang, Y. L. Ma, C. C. Chao, K. Y. Chen, and E. H. Y. Lee, "Enhanced glial cell line-derived neurotrophic factor mRNA expression upon (-)-deprenyl and melatonin treatments," Journal of Neuroscience Research, vol. 53, no. 5, pp. 593-604, 1998.

[196] D. W. Howells, M. J. Porritt, J. Y. F. Wong et al., "Reduced BDNF mRNA expression in the Parkinson's disease substantia nigra," Experimental Neurology, vol. 166, no. 1, pp. 127-135, 2000.

[197] M. Imbesi, T. Uz, and H. Manev, "Role of melatonin receptors in the effects of melatonin on BDNF and neuroprotection in mouse cerebellar neurons," Journal of Neural Transmission, vol. 115, no. 11, pp. 1495-1499, 2008.

[198] L. Zhang, H.-Q. Zhang, X.-Y. Liang, H.-F. Zhang, T. Zhang, and F.-E. Liu, "Melatonin ameliorates cognitive impairment induced by sleep deprivation in rats: role of oxidative stress, BDNF and CaMKII," Behavioural Brain Research, vol. 256, pp. 72-81, 2013.

[199] R. Molteni, F. Calabrese, S. Pisoni et al., "Synergistic mechanisms in the modulation of the neurotrophin BDNF in the rat prefrontal cortex following acute agomelatine administration," The World Journal of Biological Psychiatry, vol. 11, no. 2, pp. 148153, 2010.

[200] S. Klongpanichapak, P. Phansuwan-Pujito, M. Ebadi, and P. Govitrapong, "Melatonin inhibits amphetamine-induced increase in $\alpha$-synuclein and decrease in phosphorylated tyrosine hydroxylase in SK-N-SH cells," Neuroscience Letters, vol. 436, no. 3, pp. 309-313, 2008.

[201] K. Sae-Ung, K. Uéda, P. Govitrapong, and P. PhansuwanPujito, "Melatonin reduces the expression of alpha-synuclein in the dopamine containing neuronal regions of amphetaminetreated postnatal rats," Journal of Pineal Research, vol. 52, no. 1, pp. 128-137, 2012.

[202] C.-F. Chang, H.-J. Huang, H.-C. Lee, K.-C. Hung, R.-T. Wu, and A. M.-Y. Lin, "Melatonin attenuates kainic acid-induced neurotoxicity in mouse hippocampus via inhibition of autophagy and $\alpha$-synuclein aggregation," Journal of Pineal Research, vol. 52, no. 3, pp. 312-321, 2012.

[203] C. Freire and S. Koifman, "Pesticide exposure and Parkinson's disease: epidemiological evidence of association," NeuroToxicology, vol. 33, no. 5, pp. 947-971, 2012.

[204] H. Zhou, J. Chen, X. Lu et al., "Melatonin protects against rotenone-induced cell injury via inhibition of Omi and Baxmediated autophagy in Hela cells," Journal of Pineal Research, vol. 52, no. 1, pp. 120-127, 2012.

[205] G. L. Willis, C. Moore, and S. M. Armstrong, "A historical justification for and retrospective analysis of the systematic application of light therapy in Parkinson's disease," Reviews in the Neurosciences, vol. 23, no. 2, pp. 199-226, 2012.

[206] C. A. M. Medeiros, P. F. Carvalhedo de Bruin, L. A. Lopes, M. C. Magalhães, M. de Lourdes Seabra, and V. M. Sales de Bruin, "Effect of exogenous melatonin on sleep and motor dysfunction in Parkinson's disease. A randomized, double blind, placebocontrolled study," Journal of Neurology, vol. 254, no. 4, pp. 459464, 2007.

[207] J. I. Chuang and M. T. Lin, "Pharmacological effects of melatonin treatment on both locomotor activity and brain serotonin release in rats," Journal of Pineal Research, vol. 17, no. 1, pp. 11-16, 1994.

[208] G. L. Willis and S. M. Armstrong, "A therapeutic role for melatonin antagonism in experimental models of Parkinson's disease," Physiology \& Behavior, vol. 66, no. 5, pp. 785-795, 1999.

[209] S. Rutten, C. Vriend, O. A. van den Heuvel, J. H. Smit, H. W. Berendse, and Y. D. van der Werf, "Bright light therapy in Parkinson's disease: an overview of the background and evidence," Parkinson's Disease, vol. 2012, Article ID 767105, 9 pages, 2012.

[210] G. L. Willis and E. J. D. Turner, "Primary and secondary features of Parkinson's disease improve with strategic exposure to bright light: a case series study," Chronobiology International, vol. 24, no. 3, pp. 521-537, 2007.

[211] S. Paus, T. Schmitz-Hübsch, U. Wüllner, A. Vogel, T. Klockgether, and M. Abele, "Bright light therapy in Parkinson's disease: a pilot study," Movement Disorders, vol. 22, no. 10, pp. 1495-1498, 2007.

[212] G. L. Willis and A. D. Robertson, "Recovery from experimental Parkinson's disease in the 1-methyl-4-phenyl-1, 2,3,6tetrahydropyridine hydrochloride treated marmoset with the melatonin analogue ML-23," Pharmacology Biochemistry and Behavior, vol. 80, no. 1, pp. 9-26, 2005.

[213] G. L. Willis, "Intraocular microinjections repair experimental Parkinson's disease," Brain Research, vol. 1217, pp. 119-131, 2008.

[214] I. Bodis-Wollner, "Visual deficits related to dopamine deficiency in experimental animals and Parkinson's disease patients," Trends in Neurosciences, vol. 13, no. 7, pp. 296-302, 1990.

[215] N. Zisapel, "Melatonin-dopamine interactions: from basic neurochemistry to a clinical setting," Cellular and Molecular Neurobiology, vol. 21, no. 6, pp. 605-616, 2001.

[216] K.-R. Shieh, Y.-S. Chu, and J.-T. Pan, "Circadian change of dopaminergic neuron activity: effects of constant light and melatonin," NeuroReport, vol. 8, no. 9-10, pp. 2283-2287, 1997.

[217] H. Khaldy, J. León, G. Escames, L. Bikjdaouene, J. J. García, and D. Acuña-Castroviejo, "Circadian rhythms of dopamine and dihydroxyphenyl acetic acid in the mouse striatum: effects of pinealectomy and of melatonin treatment," Neuroendocrinology, vol. 75, no. 3, pp. 201-208, 2002.

[218] A. Iranzo, "Sleep in neurodegenerative diseases," Sleep Medicine Clinics, vol. 11, no. 1, pp. 1-18, 2016.

[219] R. D. Abbott, G. W. Ross, L. R. White et al., "Excessive daytime sleepiness and subsequent development of Parkinson disease," Neurology, vol. 65, no. 9, pp. 1442-1446, 2005.

[220] L. K. Tholfsen, J. P. Larsen, J. Schulz, O.-B. Tysnes, and M. D. Gjerstad, "Development of excessive daytime sleepiness in early Parkinson disease," Neurology, vol. 85, no. 2, pp. 162-168, 2015.

[221] L. M. Trotti and D. L. Bliwise, "Treatment of the sleep disorders associated with Parkinson's disease," Neurotherapeutics, vol. 11, no. 1, pp. 68-77, 2014.

[222] K. Mishima, M. Okawa, Y. Hishikawa, S. Hozumi, H. Hori, and K. Takahashi, "Morning bright light therapy for sleep and behavior disorders in elderly patients with dementia," Acta Psychiatrica Scandinavica, vol. 89, no. 1, pp. 1-7, 1994.

[223] A. F. G. Leentjens, B. Scholtissen, F. W. Vreeling, and F. R. J. Verhey, "The serotonergic hypothesis for depression in Parkinson's disease: an experimental approach," Neuropsychopharmacology, vol. 31, no. 5, pp. 1009-1015, 2006.

[224] P. Jennum, J. A. Christensen, and M. Zoetmulder, "Neurophysiological basis of rapid eye movement sleep behavior disorder: informing future drug development," Nature and Science of Sleep, vol. 8, pp. 107-120, 2016. 
[225] C. H. Schenck, B. F. Boeve, and M. W. Mahowald, "Delayed emergence of a parkinsonian disorder or dementia in $81 \%$ of older men initially diagnosed with idiopathic rapid eye movement sleep behavior disorder: a 16-year update on a previously reported series," Sleep Medicine, vol. 14, no. 8, pp. 744-748, 2013.

[226] A. Iranzo, E. Tolosa, E. Gelpi et al., "Neurodegenerative disease status and post-mortem pathology in idiopathic rapid-eyemovement sleep behaviour disorder: An Observational Cohort Study," The Lancet Neurology, vol. 12, no. 5, pp. 443-453, 2013.

[227] L. Plomhause, K. Dujardin, A. Duhamel et al., "Rapid eye movement sleep behavior disorder in treatment-naïve Parkinson disease patients," Sleep Medicine, vol. 14, no. 10, pp. 1035-1037, 2013.

[228] J.-F. Gagnon, M.-A. Bédard, M. L. Fantini et al., "REM sleep behavior disorder and REM sleep without atonia in Parkinson's disease," Neurology, vol. 59, no. 4, pp. 585-589, 2002.

[229] F. Sixel-Döring, E. Trautmann, B. Mollenhauer, and C. Trenkwalder, "Associated factors for REM sleep behavior disorder in Parkinson disease," Neurology, vol. 77, no. 11, pp. 10481054, 2011.

[230] M. D. Gjerstad, B. Boeve, T. Wentzel-Larsen, D. Aarsland, and J. P. Larsen, "Occurrence and clinical correlates of REM sleep behaviour disorder in patients with Parkinson's disease over time," Journal of Neurology, Neurosurgery and Psychiatry, vol. 79, no. 4, pp. 387-391, 2008.

[231] D. Kunz and F. Bes, "Melatonin as a therapy in REM sleep behavior disorder patients: an open-labeled pilot study on the possible influence of melatonin on REM-sleep regulation," Movement Disorders, vol. 14, no. 3, pp. 507-511, 1999.

[232] A. Ylikoski, K. Martikainen, M. Sieminski, and M. Partinen, "Parkinson's disease and insomnia," Neurological Sciences, vol. 36, no. 11, pp. 2003-2010, 2015.

[233] C. Trenkwalder, B. Kies, M. Rudzinska et al., "Rotigotine effects on early morning motor function and sleep in Parkinson's disease: a double-blind, randomized, placebo-controlled study (RECOVER)," Movement Disorders, vol. 26, no. 1, pp. 90-99, 2011.

[234] K. Ray Chaudhuri, P. Martinez-Martin, K. A. Rolfe et al., "Improvements in nocturnal symptoms with ropinirole prolonged release in patients with advanced Parkinson's disease," European Journal of Neurology, vol. 19, no. 1, pp. 105-113, 2012.

[235] M. Zibetti, M. Rizzone, A. Merola et al., "Sleep improvement with levodopa/carbidopa intestinal gel infusion in Parkinson disease," Acta Neurologica Scandinavica, vol. 127, no. 5, pp. e28e32, 2013.

[236] B. Guardiola-Lemaître, A. Lenègre, and R. D. Porsolt, "Combined effects of diazepam and melatonin in two tests for anxiolytic activity in the mouse," Pharmacology, Biochemistry and Behavior, vol. 41, no. 2, pp. 405-408, 1992.

[237] S. Rios Romenets, L. Creti, C. Fichten et al., "Doxepin and cognitive behavioural therapy for insomnia in patients with Parkinson's disease-a randomized study," Parkinsonism and Related Disorders, vol. 19, no. 7, pp. 670-675, 2013.

[238] W. Ding, L.-J. Ding, F.-F. Li, Y. Han, and L. Mu, "Neurodegeneration and cognition in Parkinson's disease: a review," European Review for Medical and Pharmacological Sciences, vol. 19, no. 12, pp. 2275-2281, 2015.

[239] T. Foltynie, C. E. G. Brayne, T. W. Robbins, and R. A. Barker, "The cognitive ability of an incident cohort of Parkinson's patients in the UK. The CamPaIGN study," Brain, vol. 127, part 3, pp. 550-560, 2004.
[240] M. Richards, L. J. Cote, and Y. Stern, "Executive function in Parkinson's disease: set-shifting or set-maintenance?" Journal of Clinical and Experimental Neuropsychology, vol. 15, no. 2, pp. 266-279, 1993.

[241] A. Montse, V. Pere, J. Carme, V. Francesc, and T. Eduardo, "Visuospatial deficits in Parkinson's disease assessed by judgment of line orientation test: error analyses and practice effects," Journal of Clinical and Experimental Neuropsychology, vol. 23, no. 5, pp. 592-598, 2001.

[242] E. Mak, J. Zhou, L. C. S. Tan, W. L. Au, Y. Y. Sitoh, and N. Kandiah, "Cognitive deficits in mild Parkinson's disease are associated with distinct areas of grey matter atrophy," Journal of Neurology, Neurosurgery and Psychiatry, vol. 85, no. 5, pp. 576580, 2014.

[243] Y. Takahashi and T. Okada, "Involvement of the nitric oxide cascade in melatonin-induced inhibition of long-term potentiation at hippocampal CA1 synapses," Neuroscience Research, vol. 69, no. 1, pp. 1-7, 2011.

[244] G. Ramírez-Rodríguez, N. M. Vega-Rivera, G. Benítez-King, M. Castro-García, and L. Ortíz-López, "Melatonin supplementation delays the decline of adult hippocampal neurogenesis during normal aging of mice," Neuroscience Letters, vol. 530, no. 1, pp. 53-58, 2012.

[245] V. K. Datieva, A. V. Rosinskaya, and O. S. Levin, "The use of melatonin in the treatment of chronic fatigue syndrome and circadian rhythm disorders in Parkinson's disease," Zh Nevrol Psikhiatr, vol. 113, no. 7, pp. 77-81, 2013.

[246] C. Capitelli, A. Sereniki, M. M. S. Lima, A. B. Reksidler, S. Tufik, and M. A. B. F. Vital, "Melatonin attenuates tyrosine hydroxylase loss and hypolocomotion in MPTP-lesioned rats," European Journal of Pharmacology, vol. 594, no. 1-3, pp. 101-108, 2008.

[247] V. Bertaina-Anglade, C. Drieu-La-Rochelle, E. Mocaër, and L. Seguin, "Memory facilitating effects of agomelatine in the novel object recognition memory paradigm in the rat," Pharmacology Biochemistry and Behavior, vol. 98, no. 4, pp. 511-517, 2011.

[248] P. He, X. Ouyang, S. Zhou et al., "A novel melatonin agonist NeuP11 facilitates memory performance and improves cognitive impairment in a rat model of Alzheimer' disease," Hormones and Behavior, vol. 64, no. 1, pp. 1-7, 2013.

[249] G. Baydas, M. Özer, A. Yasar, M. Tuzcu, and S. T. Koz, "Melatonin improves learning and memory performances impaired by hyperhomocysteinemia in rats," Brain Research, vol. 1046, no. 1-2, pp. 187-194, 2005.

[250] M. E. Pushpanathan, A. M. Loftus, M. G. Thomas, N. Gasson, and R. S. Bucks, "The relationship between sleep and cognition in Parkinson's disease: a meta-analysis," Sleep Medicine Reviews, vol. 26, pp. 21-32, 2016.

[251] S. Comai and G. Gobbi, "Unveiling the role of melatonin MT2 receptors in sleep, anxiety and other neuropsychiatric diseases: a novel target in psychopharmacology," Journal of Psychiatry and Neuroscience, vol. 39, no. 1, pp. 6-21, 2014.

[252] D. Aarsland, S. Påhlhagen, C. G. Ballard, U. Ehrt, and P. Svenningsson, "Depression in Parkinson disease-epidemiology, mechanisms and management," Nature Reviews Neurology, vol. 8, no. 1, pp. 35-47, 2012.

[253] J. W. Cooney and M. Stacy, "Neuropsychiatric issues in Parkinson's disease," Current Neurology and Neuroscience Reports, vol. 16, no. 5, article 49, 2016.

[254] O. Riedel, J. Klotsche, A. Spottke et al., "Frequency of dementia, depression, and other neuropsychiatric symptoms in 1,449 
outpatients with Parkinson's disease," Journal of Neurology, vol. 257, no. 7, pp. 1073-1082, 2010.

[255] S. E. Starkstein, J. P. Fedoroff, T. R. Price, R. Leiguarda, and R. G. Robinson, "Anosognosia in patients with cerebrovascular lesions. A study of causative factors," Stroke, vol. 23, no. 10, pp. 1446-1453, 1992.

[256] E. L. Jacob, N. M. Gatto, A. Thompson, Y. Bordelon, and B. Ritz, "Occurrence of depression and anxiety prior to Parkinson's disease," Parkinsonism and Related Disorders, vol. 16, no. 9, pp. 576-581, 2010.

[257] A. Alonso, L. A. García Rodríguez, G. Logroscino, and M. A. Hernán, "Use of antidepressants and the risk of Parkinson's disease: a prospective study," Journal of Neurology, Neurosurgery and Psychiatry, vol. 80, no. 6, pp. 671-674, 2009.

[258] U. Walter, D. Dressler, A. Wolters, M. Wittstock, and R. Benecke, "Transcranial brain sonography findings in clinical subgroups of idiopathic Parkinson's disease," Movement Disorders, vol. 22, no. 1, pp. 48-54, 2007.

[259] H. Braak and K. Del Tredici, "A new look at the corticostriatalthalamocortical circuit in sporadic Parkinson's disease," Der Nervenarzt, vol. 79, no. 12, pp. 1440-1445, 2008.

[260] V. Micale, A. Arezzi, L. Rampello, and F. Drago, "Melatonin affects the immobility time of rats in the forced swim test: the role of serotonin neurotransmission," European Neuropsychopharmacology, vol. 16, no. 7, pp. 538-545, 2006.

[261] M. Mantovani, R. Pértile, J. B. Calixto, A. R. S. Santos, and A. L. S. Rodrigues, "Melatonin exerts an antidepressant-like effect in the tail suspension test in mice: evidence for involvement of $\mathrm{N}$ methyl-D-aspartate receptors and the L-arginine-nitric oxide pathway," Neuroscience Letters, vol. 343, no. 1, pp. 1-4, 2003.

[262] R. W. Binfaré, M. Mantovani, J. Budni, A. R. S. Santos, and A. L. S. Rodrigues, "Involvement of dopamine receptors in the antidepressant-like effect of melatonin in the tail suspension test," European Journal of Pharmacology, vol. 638, no. 1-3, pp. 78-83, 2010.

[263] B. C. Detanico, Â. L. Piato, J. J. Freitas et al., "Antidepressant-like effects of melatonin in the mouse chronic mild stress model," European Journal of Pharmacology, vol. 607, no. 1-3, pp. 121-125, 2009.

[264] S. Rivara, D. Pala, A. Bedini, and G. Spadoni, "Therapeutic uses of melatonin and melatonin derivatives: a patent review (20122014)," Expert Opinion on Therapeutic Patents, vol. 25, no. 4, pp. 425-441, 2015.

[265] I. N. Karatsoreos and B. S. McEwen, "Timing is everything: a collection on how clocks affect resilience in biological systems," F1000Research, vol. 3, article 273, 2014.

[266] S. J. Bolitho, S. L. Naismith, S. M. W. Rajaratnam et al., "Disturbances in melatonin secretion and circadian sleep-wake regulation in Parkinson disease," Sleep Medicine, vol. 15, no. 3, pp. 342-347, 2014.

[267] T. Yamanishi, H. Tachibana, M. Oguru et al., "Anxiety and depression in patients with Parkinson's disease," Internal Medicine, vol. 52, no. 5, pp. 539-545, 2013.

[268] N. N. N. W. Dissanayaka, E. White, J. D. O'Sullivan, R. Marsh, N. A. Pachana, and G. J. Byrne, "The clinical spectrum of anxiety in Parkinson's disease," Movement Disorders, vol. 29, no. 8, pp. 967-975, 2014.

[269] R. D. S. Prediger, F. C. Matheus, M. L. Schwarzbold, M. M. S. Lima, and M. A. B. F. Vital, "Anxiety in Parkinson's disease: a critical review of experimental and clinical studies," Neuropharmacology, vol. 62, no. 1, pp. 115-124, 2012.
[270] N. N. W. Dissanayaka, A. Sellbach, S. Matheson et al., "Anxiety disorders in Parkinson's disease: prevalence and risk factors," Movement Disorders, vol. 25, no. 7, pp. 838-845, 2010.

[271] G. M. Pontone, J. R. Williams, K. E. Anderson et al., "Prevalence of anxiety disorders and anxiety subtypes in patients with Parkinson's disease," Movement Disorders, vol. 24, no. 9, pp. 1333-1338, 2009.

[272] S.-M. Jiang, Y.-S. Yuan, Q. Tong et al., “The association between clinically relevant anxiety and other non-motor symptoms in Parkinson's disease," Neurological Sciences, vol. 36, no. 11, pp. 2105-2109, 2015.

[273] N. N. W. Dissanayaka, E. Torbey, and N. A. Pachana, "Anxiety rating scales in Parkinson's disease: a critical review updating recent literature," International Psychogeriatrics, vol. 27, no. 11, pp. 1777-1784, 2015.

[274] M. P. Broen, S. Köhler, A. J. Moonen et al., "Modeling anxiety in Parkinson's disease," Movement Disorders, vol. 31, no. 3, pp. 310-316, 2016.

[275] S. Rutten, I. Ghielen, C. Vriend et al., "Anxiety in Parkinson's disease: symptom dimensions and overlap with depression and autonomic failure," Parkinsonism and Related Disorders, vol. 21, no. 3, pp. 189-193, 2015.

[276] E. C. Lauterbach, A. Freeman, and R. L. Vogel, "Correlates of generalized anxiety and panic attacks in dystonia and Parkinson disease," Cognitive and Behavioral Neurology, vol. 16, no. 4, pp. 225-233, 2003.

[277] A. Tessitore, A. R. Hariri, F. Fera et al., "Dopamine modulates the response of the human amygdala: a study in Parkinson's disease," The Journal of Neuroscience, vol. 22, no. 20, pp. 9099 9103, 2002.

[278] J. J. Chen and L. Marsh, "Anxiety in Parkinson's disease: identification and management," Therapeutic Advances in Neurological Disorders, vol. 7, no. 1, pp. 52-59, 2014.

[279] K. Del Tredici and H. Braak, "Dysfunction of the locus coeruleus-norepinephrine system and related circuitry in Parkinson's disease-related dementia," Journal of Neurology, Neurosurgery and Psychiatry, vol. 84, no. 7, pp. 774-783, 2013.

[280] N. Wee, N. Kandiah, S. Acharyya et al., "Depression and anxiety are co-morbid but dissociable in mild Parkinson's disease: A Prospective Longitudinal Study of patterns and predictors," Parkinsonism and Related Disorders, vol. 23, pp. 50-56, 2016.

[281] M. Naguib and A. H. Samarkandi, "The comparative doseresponse effects of melatonin and midazolam for premedication of adult patients: a double-blinded, placebo-controlled study," Anesthesia and Analgesia, vol. 91, no. 2, pp. 473-479, 2000.

[282] F. Yousaf, E. Seet, L. Venkatraghavan, A. Abrishami, and F. Chung, "Efficacy and safety of melatonin as an anxiolytic and analgesic in the perioperative period: a qualitative systematic review of randomized trials," Anesthesiology, vol. 113, no. 4, pp. 968-976, 2010.

[283] G. Perna, A. Alciati, A. Riva, W. Micieli, and D. Caldirola, "Long-term pharmacological treatments of anxiety disorders: an updated systematic review," Current Psychiatry Reports, vol. 18 , no. 3, article 23, 2016.

[284] J. A. S. Crippa, J. E. C. Hallak, A. W. Zuardi, M. H. N. Chagas, J. Quevedo, and A. E. Nardi, "Agomelatine in the treatment of social anxiety disorder," Progress in Neuro-Psychopharmacology and Biological Psychiatry, vol. 34, no. 7, pp. 1357-1358, 2010.

[285] K. M. Huijbregts, N. M. Batelaan, J. Schonenberg, G. Veen, and A. J. van Balkom, "Agomelatine as a novel treatment option in panic disorder, results from an 8-week open-label trial," Journal of Clinical Psychopharmacology, vol. 35, no. 3, pp. 336-338, 2015. 
[286] Y. B. Kalyn, T. P. Safarova, O. B. Yakovleva et al., "Experience of the antidepressive therapy with valdoxan (agomelatine) in a psychogeriatric unit of the psychiatric hospital," Zhurnal nevrologii i psikhiatrii im. S.S. Korsakova, vol. 115, no. 11, pp. 5562, 2015.

[287] L. Niles, "Melatonin interaction with the benzodiazepineGABA receptor complex in the CNS," Advances in Experimental Medicine and Biology, vol. 294, pp. 267-277, 1991. 


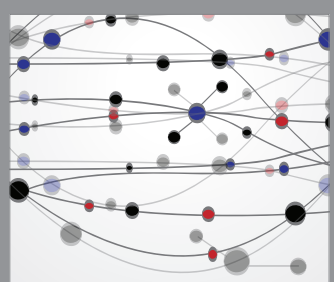

The Scientific World Journal
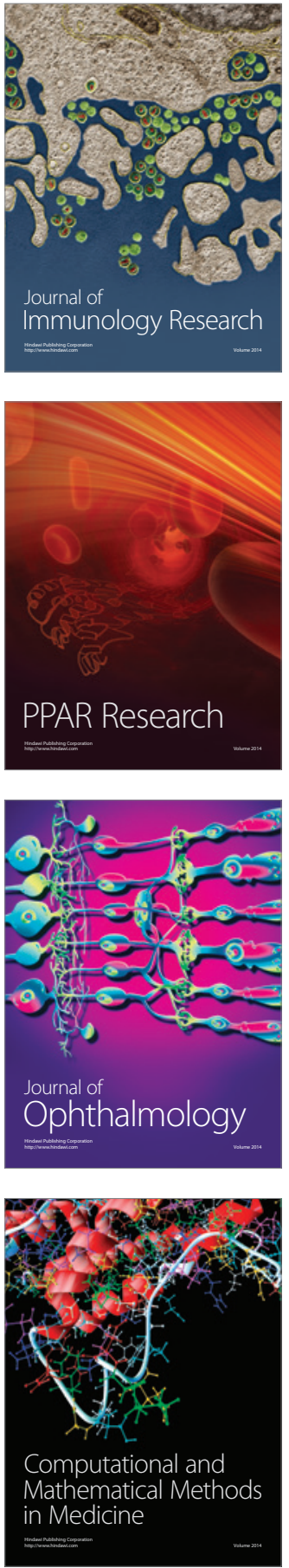

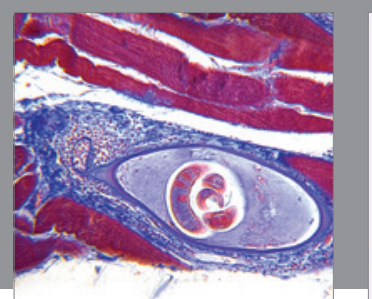

Gastroenterology Research and Practice

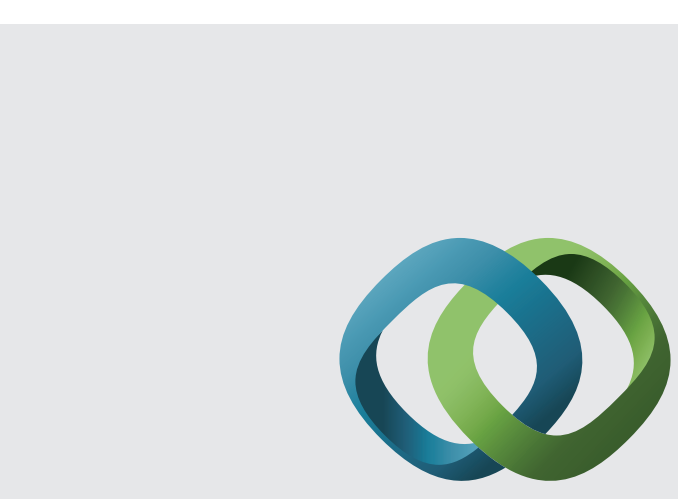

\section{Hindawi}

Submit your manuscripts at

http://www.hindawi.com
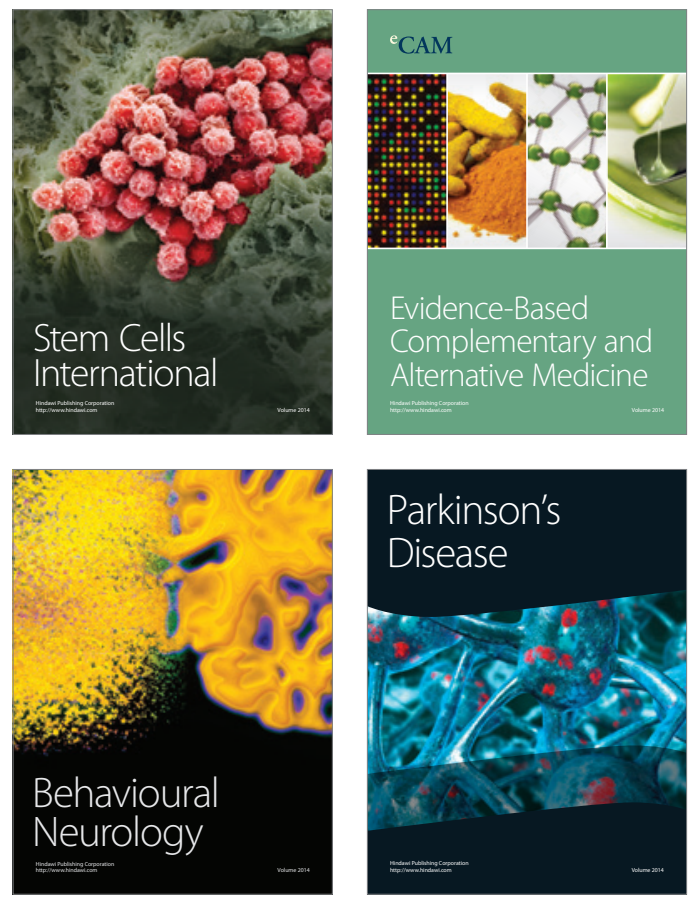
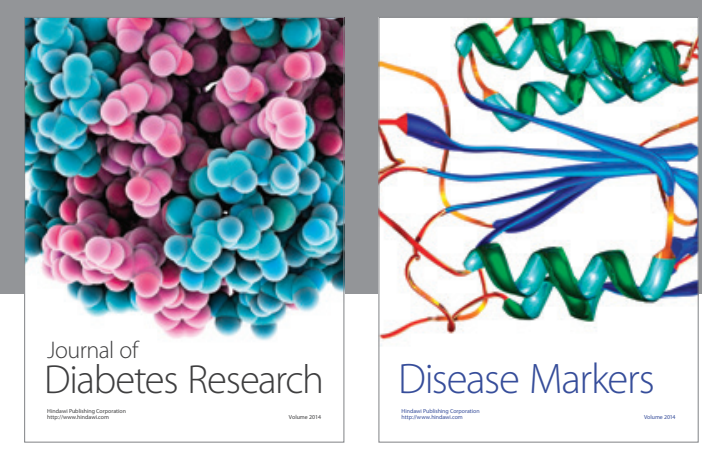

Disease Markers
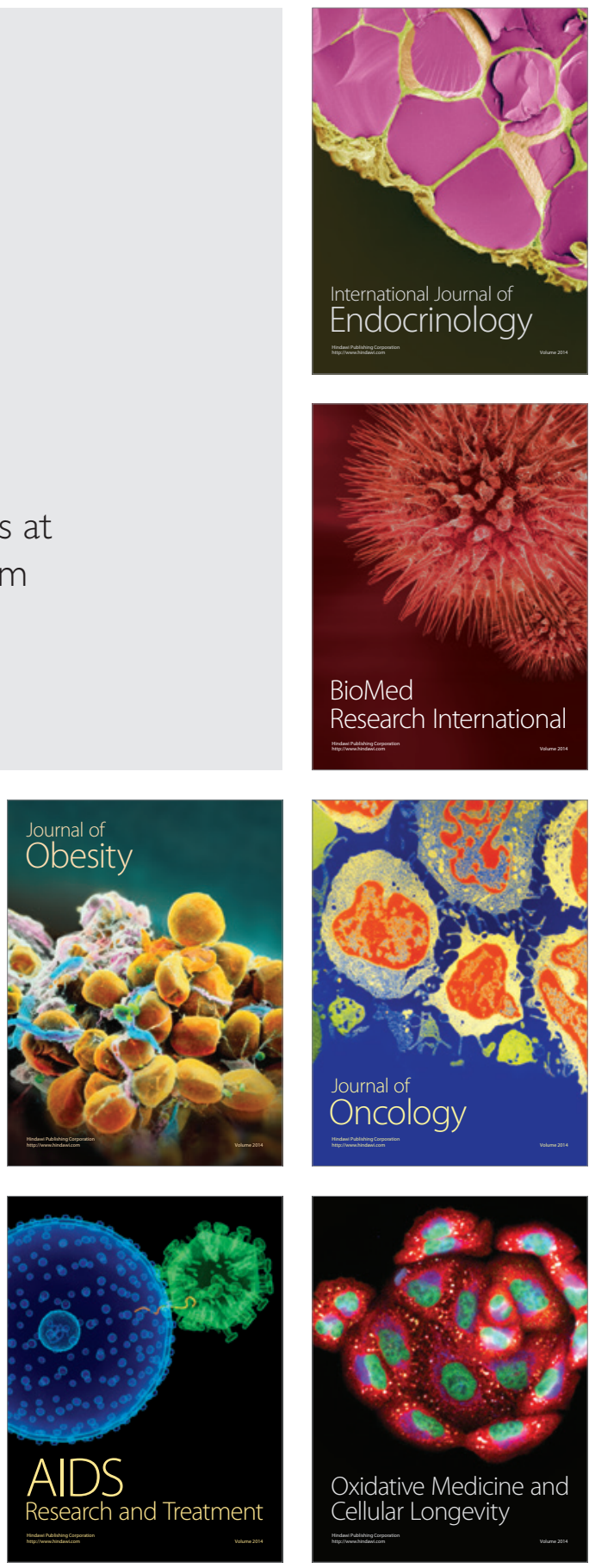